PREPARED FOR THE U.S. DEPARTMENT OF ENERGY, UNDER CONTRACT DE-AC02-76CH03073

PPPL-3842

PPPL-3842

UC-70

Determination of Diameter and Index

of Refraction of Textile Fibers

by Laser Backscattering

by

H. Okuda, B. Stratton, L. Meixler, P. Efthimion, and D. Mansfield

July 2003

$\left.\stackrel{M}{M}\right|_{\substack{\text { PRInCETON PLASIMA } \\ \text { PHYSICS LABORATORY }}} ^{D}$

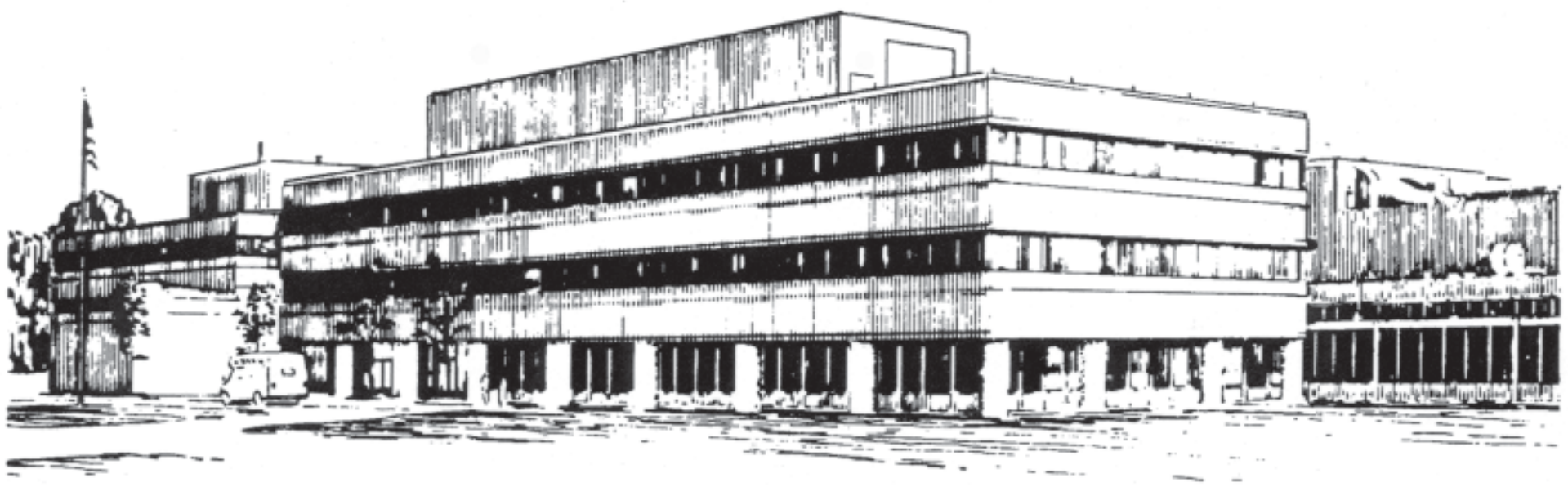

PRINCETON PLASMA PHYSICS LABORATORY PRINCETON UNIVERSITY, PRINCETON, NEW JERSEY 


\section{PPPL Reports Disclaimer}

This report was prepared as an account of work sponsored by an agency of the United States Government. Neither the United States Government nor any agency thereof, nor any of their employees, makes any warranty, express or implied, or assumes any legal liability or responsibility for the accuracy, completeness, or usefulness of any information, apparatus, product, or process disclosed, or represents that its use would not infringe privately owned rights. Reference herein to any specific commercial product, process, or service by trade name, trademark, manufacturer, or otherwise, does not necessarily constitute or imply its endorsement, recommendation, or favoring by the United States Government or any agency thereof. The views and opinions of authors expressed herein do not necessarily state or reflect those of the United States Government or any agency thereof.

\section{Availability}

This report is posted on the U.S. Department of Energy's Princeton Plasma Physics Laboratory Publications and Reports web site in Fiscal Year 2003. The home page for PPPL Reports and Publications is: http://www.pppl.gov/pub_report/

DOE and DOE Contractors can obtain copies of this report from:

U.S. Department of Energy

Office of Scientific and Technical Information

DOE Technical Information Services (DTIS)

P.O. Box 62

Oak Ridge, TN 37831

Telephone: (865) 576-8401

Fax: (865) 576-5728

Email: reports@adonis.osti.gov

This report is available to the general public from:

National Technical Information Service

U.S. Department of Commerce

5285 Port Royal Road

Springfield, VA 22161

Telephone: $1-800-553-6847$ or

(703) $605-6000$

Fax: (703) 321-8547

Internet: http://www.ntis.gov/ordering.htm 


\title{
Determination of Diameter and Index of Refraction of Textile Fibers by Laser BackScattering
}

\author{
H. Okuda, B. Stratton, L. Meixler, P. Efthimion, and D.Mansfield, \\ Princeton Plasma Physics Laboratory, Princeton University, Princeton, NJ
}

KEYWORDS

Birefringence, Index of Refraction, Laser Backscatter, Fiber Analysis, On-line

\begin{abstract}
A new method was developed to determine both diameters and indices of refraction and hence the birefringence of cylindrical textile and industrial fibers and bundles by measuring intensity patterns of the scattered light over an interval of scattering angles. The measured intensity patterns are compared with theoretical predictions (Mie theory) to determine fiber diameter and index of refraction. It is shown that the method is simple and accurate and may be useful as an on-line, non-contact diagnostic tool in real time.
\end{abstract}

\section{INTRODUCTION}

The manufacture of textile fibers-called "spinning"- is a precision high-speed process. Efficient spinning benefits from better systems of process control to ensure that the desired orientation is conferred on fibers to give them strength and to control the diameter or denier of the strands.

Some discriminating measurements of the orientation of crystalline and noncrystalline phases in fibers have been carried out. (See, for example, R.J. Samuels "Structured Polymer Properties"; Wiley-Interscience, NY, 1974; D.R. Salem (editor) "Structure Formation in Polymeric Fibers," Hanser, Munich and Cincinnati, 2000).

Classically this has been done by X-ray diffraction (WAXS), recording infrared dichroism, and measuring birefringence. The last of these, birefringence, is a lumped parameter which includes contributions from chemical structure and macromolecular orientation. If 
birefringence can be measured with high precision in real time, it could serve as a parameter for on-line process control in the manufacture of textile and high-performance fibers.

Some detailed aspects of fiber structure are accessible only via specialized techniques such as Small Angle Neutron Scattering (SANS), Wide Angle X-ray Scattering (WAXS), and Small Angle X-ray Scattering (SAXS). These all involve ionizing radiation and are difficult to apply in real time on a textile spin line.

We have developed a laser light scattering measurement that can be done with simple equipment, appropriate to a textile manufacturing environment. It may also reveal useful information on orientation in polymer films and in other on-line situations. As will be shown later, laser backscatter patterns by a textile fiber are sensitive to the diameter and the index of refraction. It is therefore possible to determine these fiber characteristics (diameter and index of refraction) from the measurements of the patterns.

Sketched in Fig. 1 is a concept of the diagnostics system developed. A He/Ne laser beam is injected at normal angle onto a cylindrical textile fiber suspended vertically. A laser beam is scattered by a textile fiber over an angle of 360 degrees. Patterns of the scattered laser intensities with both parallel and perpendicular electric field components are collected by a CCD camera and stored in a computer file. While the camera can be positioned at any angle of scattering, we focus on backscatter signals where the patterns centered at the 180 degree reflection are collected and analyzed.

The intensity patterns measured by a CCD camera are compared with the patterns computed for a given diameter and index of refraction based on Mie scattering theory, and the most probable diameter and the index are determined by means of the least means square theory. By repeating the same procedures over many points of the same textile fiber, it is possible to determine the average diameter and index and the variability of a fiber caused by manufacturing processes. The same technique may also be applied to a fiber bundle consisting of many single fibers to determine the index of refraction.

\section{TWO-DIMENSIONAL LASER BACKSCATTERING}

The theory of laser beam scattering by a cylindrical dielectric material such as a synthetic fiber with circular cross-section has been computed in detail by a number of authors [See for example "Light scattering by small particles" by H.C.van der Hulse] . For normal incidence, it is straightforward to compute scattered laser beam intensities for both polarizations where the incident laser beam has an electric field polarized along the axis of the fiber (parallel polarization) or perpendicular polarization where the laser beam electric field is polarized perpendicular to the axis of a fiber (perpendicular polarization).

Shown in Figs. 2 and 3 are examples of back scattered laser beam intensity patterns computed by using Mie theory for both parallel and perpendicular polarization as a function of the scattering angle centered at 180 degrees. Here, for example, the fiber diameter is taken $\mathrm{D}=19.5 \mu \mathrm{m}$ and the index of refraction 1.640 and 1.562 for parallel and perpendicular directions of the fiber. The wavelength of the laser is $0.6328 \mu \mathrm{m}$ (He-Ne red light). Generally speaking the scattered intensity pattern is very sensitive to small variations of the diameter and the index of refraction so that the pattern can be used as a "finger print" to determine the diameter and the index of refraction of the fiber. This is because the laser 
wavelength is very short compared with the fiber diameter so that small changes in fiber characteristics comparable to the laser wavelength can be readily detected.

In order to determine the best fit of the measured patterns with computed patterns, it is necessary to compute a large number of patterns for different diameters and indices of refraction over an extended range of diameters and index of refraction. These patterns are pre-computed once and stored in a storage device to form a data base. The measured intensity pattern can then be compared with the patterns stored in the data base.

Shown in Figs. 4 and 5 are the examples of the measured parallel and perpendicular backscatter intensities of the scattered light by a CCD camera using a textile fiber manufactured by DuPont. By comparing the measured patterns with those from numerical computations for many patterns of different diameters and indices, it is possible to determine the best matched diameter and the index of refraction. In particular, the best match can be chosen by the least mean square of the difference of measured and computed intensities at each angle of scattering summed over all the angles. In this way, the most probable pattern and hence the diameter and the index, can be chosen from a large number of pre-computed patterns.

\section{TEST OF THE METHOD}

In order to demonstrate how the method works, results of analysis of 5 sets of measured parallel and perpendicular patterns are shown in Table 1. DuPont provided the fiber used in this example. For each pattern of parallel and perpendicular polarization, the most probable parallel index and diameter are first determined by minimizing the distance between the measured pattern and the computed patterns summed over an interval of scattering angles between 155 and 180 degrees. The process is then repeated to determine the second most probable diameter and index and so on, for both parallel and perpendicular polarization.

Shown at the bottom of the table are the first most probable 5 diameters and indices at each 5 locations and their overall average and the standard deviation. It is shown that the parallel index of the fiber is 1.611 with its standard deviation of $0.6325 \times 10^{-3}$, and the perpendicular index is 1.446 with its standard deviation of $0.4214 \times 10^{-2}$ so that the birefringence is 0.165 .

The fiber diameter is $19.16 \mu \mathrm{m}$ determined from the parallel patterns and $19.59 \mu \mathrm{m}$ from perpendicular pattern. The discrepancy between the two diameters suggests that the fiber does not have a perfect circular cross section.

We have applied the method to a number of textile fibers supplied to us by our industry partners. Shown in Table 2 is just an example of the method applied to 4 fibers ( 3 from DuPont and 1 from Wellman). In the example, measured patterns are taken at 30 points of the same fiber (22 for Wellman fiber) and each pattern was analyzed to determine the most probable diameter and the index of refraction. Among 30 measurements, we found several outliers whose characteristics have deviations from the average by more than 2 standard deviations.

The first column gives the overall average and the second column gives results without outliers. By comparing the industry standard values, we found the agreement between our 
results and the industry values are satisfactory. The suggested industry values for the birefringence are 0.045 for DuPont 24-A4, 0.120 for DuPont 6-20, 0.142 for DuPont 6-22 and 0.011 for Wellman 4 fibers. These figures should be compared with our measurements of 0.042 for DuPont 24-A4, 0.114 for DuPont 6-20, 0.138 for DuPont 6-22, and 0.067 for Wellman 4 fibers. Except for the Wellman 4 fibers, the agreement between the industry figures and our measurements for the birefringence are very good. The large discrepancy in birefringence for Wellman 4 fiber may be due to the small value of the birefringence which is distorted by the factors not included in the theory. One such factor is the non-circular cross-section of the fibers which will be discussed next.

\section{NON-CIRCULAR CROSS-SECTION SINGLE FIBER}

In the previous examples, we have assumed that all the fibers are homogeneous and have circular cross-sections. These assumptions made it possible to solve the laser beam scattering explicitly by means of well-known Bessel Functions (Mie theory). The actual industry fibers, on the other hand, have cross-sections far from a perfect circular shape. The non-circular nature of the cross-section may be created by many causes during the manufacturing and spinning processes. Sometimes, fibers are designed to have a noncircular cross for commercial reasons.

It is important then to establish a new mathematical method which can compute laser backscatter fields for non-circular cross-section fibers. Since the laser wavelength is a fraction of a micron, much smaller than the size of a textile fiber, we expect a small departure of the fiber cross-section from a circle, such as a small inhomogeneity or distortion from a perfect circle will cause a substantial modification of the scattered laser pattern.

In order to solve a two-dimensional scattering problem by an arbitrary shaped non-circular cross section fiber, it is necessary to use the integral equation approach which relates the scattered electric field to the cross-section of the scatterer (See, for example, "Computer Techniques for Electromagnetics", edited by R. Mittra, Pergamon Press, 1980; "Field Computation by Moment Methods", R.F. Harrington, Kriedger Publishing Co. Inc., Florida 1982). The integral equations are in turn solved by means of Boundary Integral Equation Method (See, for example, "Accurate numerical integration of singular boundary element kernels over boundaries with curvature", M.H. Lean and A. Wexler, Int. J. Num. Meth. Engng., Vol. 21, No. 2, 211-228, 1985; "Boundary integral solution of wave effects in laser-annealed silicon", in Computational Electromagnetics, edited by Z.J. Cendes, Elsevier Science Publishers, B.V. , EMACS, 1986).

Three different classes of non-circular fibers are considered. The first is an elliptic crosssection fiber, followed by a semi-circular cross-section with a flat section and the last example is a circular cross-section fiber with two different mass densities and hence two different indices of refraction. The integral equation method can be used for an arbitrary cross-section fiber including scattering by a fiber bundle consisting of many single fibers, which will be discussed later.

\section{ELLIPTIC CROSS-SECTION FIBERS}


Shown in Fig. 6 is the result of pattern matching technique applied to the elliptic crosssection fibers. Starting from a circular cross-section fiber with the diameter at $19.5 \mu \mathrm{m}$, the fiber cross-section is gradually elongated vertically to form an elliptic cross-section while the horizontal diameter remains the same. The ratio of the vertical elongation (ellipticity) to the horizontal diameter varied from 0 (circle) to 0.05 . Note the laser beam is pointing in the horizontal direction. The indices of refraction used in the computation remained the same as before (parallel index is 1.640 and the perpendicular index is 1.562). In this example, the scattered laser pattern not shown here was first computed by numerically solving the integral equations for elliptic cross-section fibers and the resultant patterns are analyzed by finding the best fit using tables of circular cross-section fibers.

As seen in Fig. 6, both the parallel and perpendicular indices decrease with the ellipticity in this example, but the birefringence that is the difference between the two remains relatively constant. Note the indices vary at about the same rate with the ellipticity.

Fig. 7 shows a similar result when the horizontal diameter is elongated while keeping the vertical diameter the same at $19.5 \mu \mathrm{m}$. In this case the indices increase with the ellipticity, but the birefringence remains about the same as before.

In practical applications in a factory floor, the orientation of the fiber cross-section with regard to the laser beam cannot be controlled. Instead the axis of the fiber will be at any angle as the fiber is moving during the spinning process. In this case it makes more sense to average the scattered patterns at many angles of orientations and analyzed the resultant averaged pattern. The result shown in Fig. 8 is obtained by pattern matching the averaged pattern over 8 different orientations separated by 45 degrees. It is interesting that in this case, both indices tend to oscillate about the means so that the birefringence also oscillates about the mean value. Depending on the accuracy of the indices required, the method used here might be a useful non-contact addition to the textile fiber diagnostics.

\section{SEMI-CIRCLE WITH FLAT SECTION FIBERS}

The next examples of non-circular cross-section fibers considered are the fibers whose cross-sections are deformed from a circle to develop a flat section. Such deformation often develops when several fibers are pressed together during the manufacturing process. A flat section is characterized by its location with respect to the laser beam and its width. Obviously the location of the flat section can be anywhere with respect to the laser beam when measured during a fast moving spinning process. The width can be represented by the arc angle corresponding to the flat section measured from the center of the fiber.

Shown in Figs. 9 and 10 are the examples of the scattered laser intensity patterns for parallel (Fig. 9) and perpendicular (Fig. 10) components by a fiber with a 45-degree flat section located at 3 o'clock position. Note the laser beam is coming from 9 o'clock position. The fiber parameters used correspond to the previous examples for a DuPont fiber whose indices of refraction are 1.640 (parallel) and 1.562 (perpendicular) respectively. Note that the patterns in this case have some resemblance to the patterns obtained for a circular fiber shown in Figs. 2 and 3.

Patterns with various arc angles and with the flat section at other locations are also computed. As the arc angle becomes larger, the patterns are found to deviate more from that 
of a full circle. Patterns are also different depending on the location of the flat section with respect to the laser beam.

Shown in Fig.11 are the results of the pattern matching analysis for those fibers with varying arc angles. In order to remove the location of the flat section, four patterns whose four locations of the flat sections are at noon, 3 o'clock, 6 o'clock and 9 o'clock position, are first averaged before the pattern is analyzed. This will correspond to a pattern measurement of a moving fiber where all the locations of the flat section will be encountered. It is very encouraging that the indices of refraction and hence the birefringence found in this example are very close to the original values, suggesting this kind of deformation will not affect the measurement of the indices by the proposed pattern matching method.

\section{CIRCULAR FIBER CONSISTING OF TWO-LAYERS OF MASS DENSITY}

The next example considered was a group of fibers whose density is non-uniform across the cross-section. In order to model such non-uniform density, circular cross-section fibers with two layers of mass density are considered. The inner layer has a higher density and hence a larger dielectric constant and index of refraction compared to the outer layer. The diameter of the inner layer was increased from zero (single layer) to $25 \%$ of the outer layer. We found that the presence of a higher density inner core does not affect the patterns and hence the usefulness of the proposed method so long as the size of the core diameter is less than about $20 \%$ of the outer diameter.

Shown in Figs. 12 and 13 are the parallel and perpendicular indices of refraction when the diameter of the inner core was chosen at $10 \%$ of the outer diameter. The core density is increased to 1.5 times the outer density. It is clear that both indices and hence the birefringence determined from the scattered patterns remain almost the same despite the increase of the core density, suggesting the presence of a small non-uniform density buildup will not affect the validity of the method. When the inner layer diameter is increased to $25 \%$ of the outer diameter, we found that the parallel index still remains almost the same but the perpendicular index deviates from the original value by as much as $5 \%$ when the core density is increased by $50 \%$. While the $5 \%$ change in the perpendicular index is much smaller than the $50 \%$ change in the core density, the error in the birefringence may be too large to be acceptable especially for weakly birefringent fibers. This is because the birefringence is often only a few $\%$ of the index itself.

\section{BUNDLE CONSISTING OF CIRCULAR SINGLE FIBERS}

So far, all the fibers considered are single fibers with various shapes of cross-sections. We found that the pattern matching diagnostics technique proposed here works well so long as the shape of a fiber is not too much different from a circle. Depending on the accuracy required, the method may be useful in some applications such as non-contact in-situ diagnostics on a textile manufacturing floor. Now, we consider laser beam scattering from

a fiber bundle consisting of many identical single fibers. A bundle is a natural form of the 
fibers used in actual textile production. If the proposed pattern matching technique works for a bundle as well as for a single fiber, the technique can be used for a bundle of fibers. At first, it seems the pattern matching technique has no chance when applied to a bundle because the scattering from a bundle will be very different from the scattering by a single circular fiber. As shown in the following, the proposed technique works even for a bundle in many cases. This happens because the scattering by a bundle consists of the sum of single scattering by an individual fiber and multiple scattering where the laser is scattered by more than one fiber. So long as the pattern from the single scattering can be identified, it is possible the proposed technique based on scattering by a single circular fiber works well.

In order to demonstrate the pattern matching by a bundle, let us first consider 4 identical circular fibers placed in the (x,y) plane along the $\mathrm{x}$ - axis and $\mathrm{y}$ - axis. The fiber is in the $\mathrm{z}$ direction. The center coordinates in the $(x, y)$ plane of these four fibers are $(-d / 2,0)$, $(d / 2,0),(0, d / 2)$, and $(0,-d / 2)$ respectively where $d$ is the distance between the two centers on the $\mathrm{x}$-axis or $\mathrm{y}$-axis. The laser beam is coming from the negative $\mathrm{x}$-axis as before. Both parallel and perpendicular components of the scattered light by such a bundle are first computed by using the integral equation method. The patterns can then be analyzed to determine the indices and hence the birefringence.

Shown in Figs. 14 is an example of the parallel intensity pattern when the distance between the two centers is equal to 7.5 diameter. The diameter and the indices of refraction for each individual fiber is $19.5 \mu \mathrm{m}$ and n-para $=1.640$ and n-perp $=1.562$ as before. It is interesting to note that there are two structures, one with short wavelength structure represented by rapid oscillations and the other with slowly varying long structure, which is the envelope of the short structures. By comparing the pattern with the pattern of a single fiber, it is straightforward to identify that the long structure corresponds to the scattering by individual single fibers, whereas the short structure must correspond to multiple scattering by more than one fiber. It is true that the larger the scatterer is, the shorter the scattered wavelength is.

When the pattern shown in Fig.14 is analyzed by the pattern matching technique using tables of single circular fibers, it is not surprising that the present technique can correctly predict parallel and perpendicular indices and hence the birefringence in this case. This will be discussed later.

When the fibers are nested closer in a bundle, it becomes more difficult to separate single scattering from multiple scattering. This is demonstrated in Fig. 15 where the distance between the two centers is equal to 1.5 fiber diameter. Note the closest distance is 1.4142 fiber diameter when two fibers are touching. There are similarities and differences between the pattern in Fig. 15 and the envelope of the patterns in Fig. 14. Since the four fibers are almost touching each other in this case, two separate scale lengths, fiber diameter and the distance between the fibers, are not separated very well.

Shown in Fig.16 is the parallel and perpendicular indices of refraction determined by the present pattern matching technique when the distance between two fibers are varied from 1.5 fiber diameters to 7.5 fiber diameters. As expected, the indices of refraction agree very well when the distance between the two centers is larger than about 3 times the diameter. When the distance is shorter than that, indices deviate from the correct values because the scattering pattern cannot be clearly separated between short and long structures.

Real textile bundles have many more single fibers so it is interesting to ask what can be expected from such bundles. The integral equation method should work with any number of single fibers. As in any computational however, a practical limit exists which is 
determined by the memory size and the computing time available. In practice, a bundle consisting of several tens of single fibers should pose no problem. We have computed scattering patterns for bundles consisting of many single fibers including up to 37 single fibers in a bundle. The computed patterns become more complex as the number of single fibers is increased.

Shown in Fig. 17 and 18 are examples of parallel and perpendicular patterns for a bundle consisting of 19 fibers of the same single fiber. The distance between the two fibers is kept small at about 2 diameters. Both short structures and long structures can be seen in these patterns. Those patterns are then analyzed by pattern matching technique to determine indices of refraction and hence the birefringence. We found that regardless the number of the single fibers in a bundle and regardless the exact configuration of the fibers to form a bundle, the previous conclusion found for a bundle consisting of four fibers holds true. So long as the fibers are not nested very closely such that the distance between the nearest two fibers is more than 2 fiber diameters apart, it is expected that the pattern matching technique can be used to determine the index of refraction fairly accurately.

\section{CIRCULAR SINGLE FIBERS WITH ABSORPTION}

The last example considered was effect of light absorption on the scattering patterns. While many textile fibers have little absorption of the laser light, it is also true to expect some degree of light absorption when dealing with real textile fibers. Here we consider only a case where the main effect of the absorption can be modeled by adding an imaginary part to the index of refraction. The imaginary part can be considered an absorption coefficient since it represents the degree of amplitude attenuation as the light penetrates into the fiber. The total absorption depends not only on the absorption but also on the laser wavelength and the size of the fiber. Here we consider again the same DuPont fiber using the red $\mathrm{He} / \mathrm{Ne}$ laser. The diameter of the fiber is $19.5 \mu \mathrm{m}$ and the real part of the index of refraction is 1.640 in the parallel direction and 1.562 perpendicular to the fiber axis.

Shown in Figs. 19 and 20 are the computed parallel scattering patterns when the index of refraction is modified to $1.640 *(1,-0.001)$ and $1.640 *(1,-0.005)$ respectively. Comparing these Figures with Fig. 2 which corresponds to the case of no absorption, it is clear that the patterns show little change when the absorption is $0.1 \%$ even though the intensity is reduced by a factor 5 or so. In this case, the pattern matching technique can correctly identify the index of refraction. When the absorption is increased to $0.5 \%$, the intensity is reduced by a factor of 50 as shown in Fig. 20. Furthermore, the pattern itself is modified loosing fine structures observed for a smaller absorption. Note that the effect of the absorption depends on the fiber diameter, so even a small absorption such as $0.1 \%$ cannot be ignored when the diameter of a fiber becomes larger.

\section{ACKNOWLEDGEMENTS}

It is our pleasure to acknowledge support and encouragement by our industry partners during the course of the AMTEX project. In particular, Dr. Alan Kennedy of DuPont, Dr. 
Don Burlone of Wellman and Dr. Gail Eaton of Princeton Textile Research Institute shared with us their expertise of textile physics and guided us throughout the course of the project. One of the authors (HO) would like to thank Dr. Meng Lean of Xerox Corporation for his expert consulting on the boundary integral equation method. This work was supported by the US Department of Energy. 


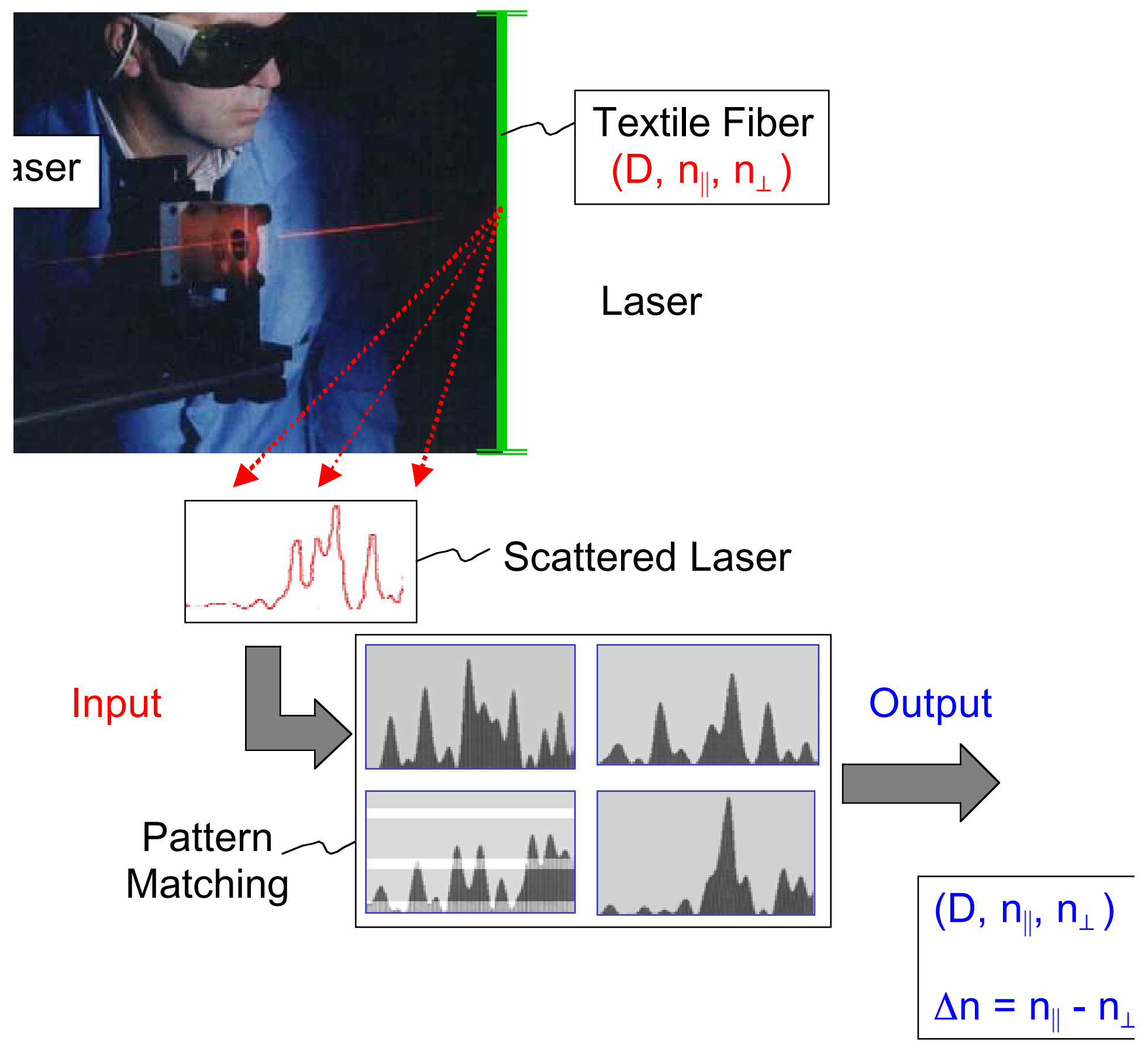

AMTEX PROJECT AT PPPL

Fig 1 
Fig. 2

Computed parallel intensity pattern

Diameter $=19.5$ micron

$\mathrm{n}$-para $=1.640$

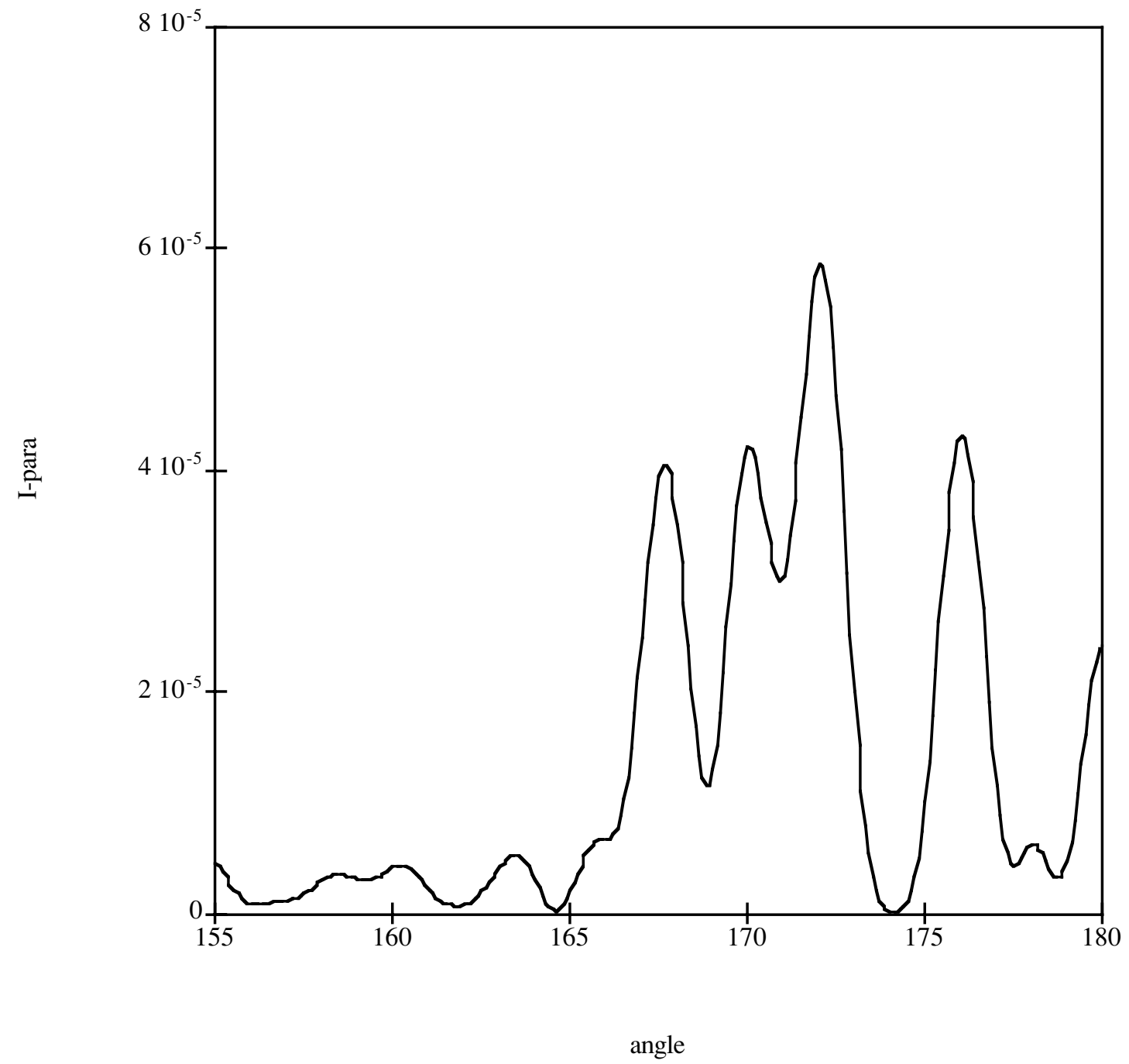


Fig. 3

Computed perpendicular intensity pattern

Diameter $=19.5$ micron

$\mathrm{n}$-perp $=1.562$

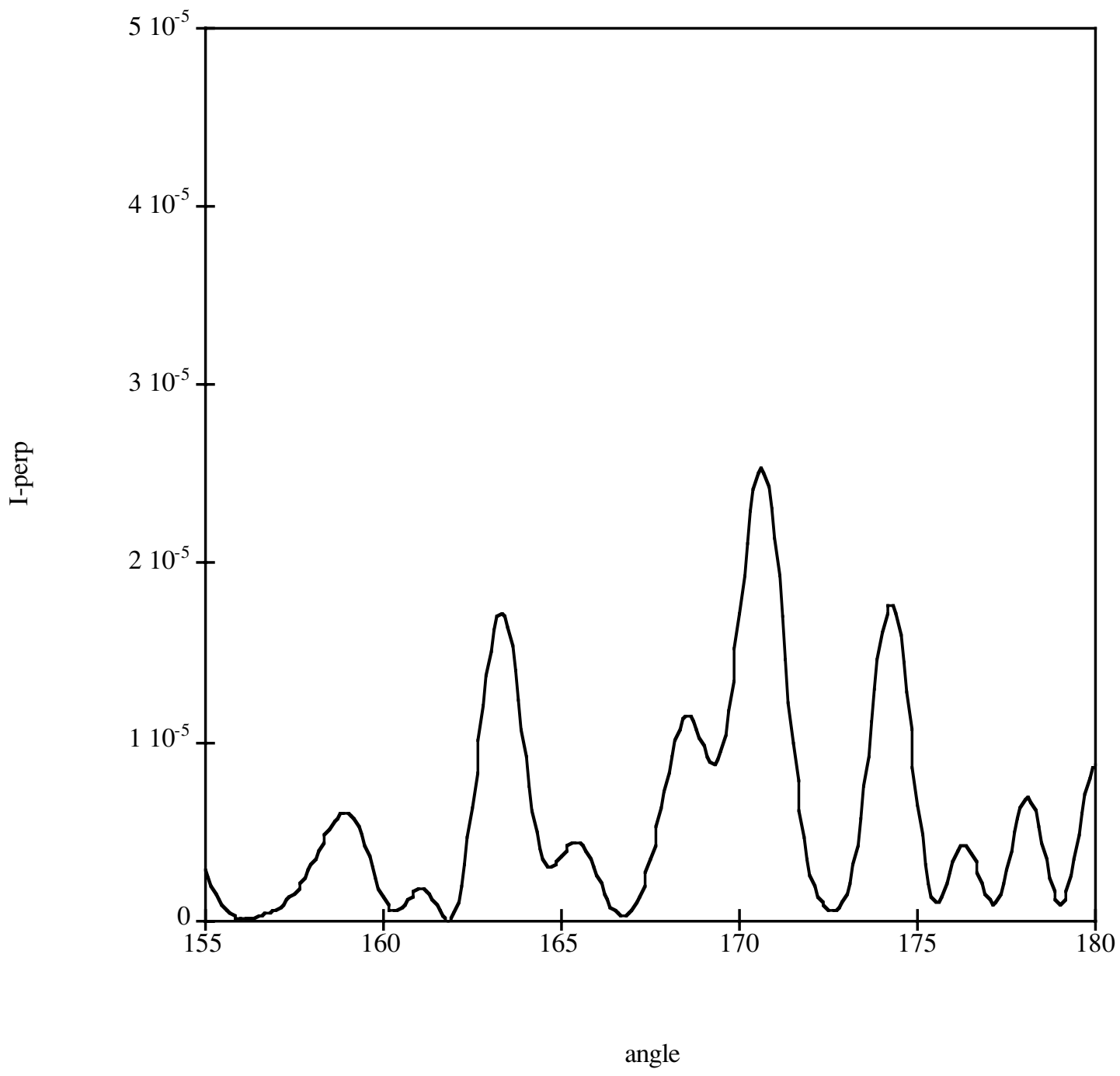


Fig. 4

Measured parallel intensity pattern laser wavelength $=0.6328$ micron

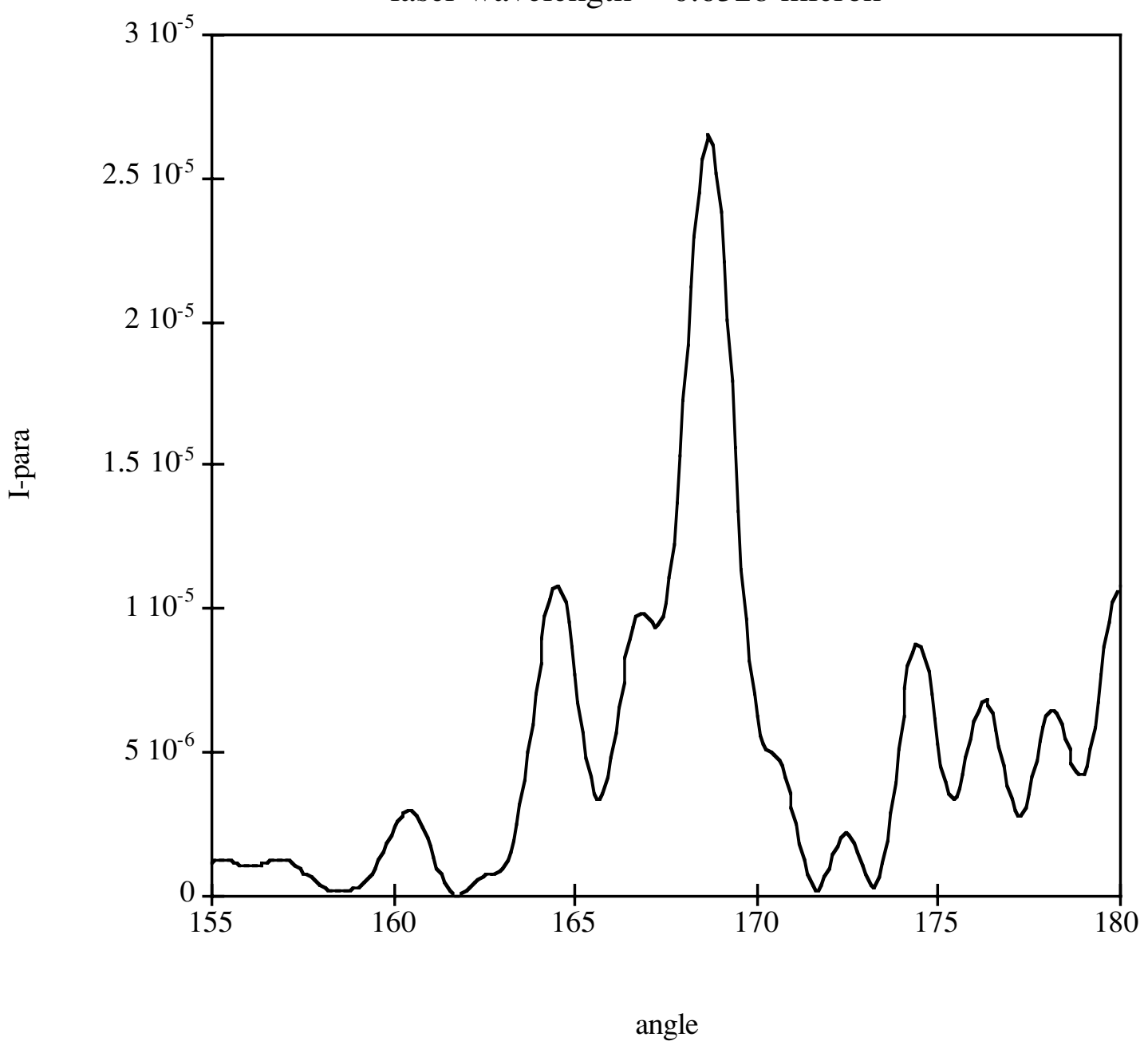


Fig. 5

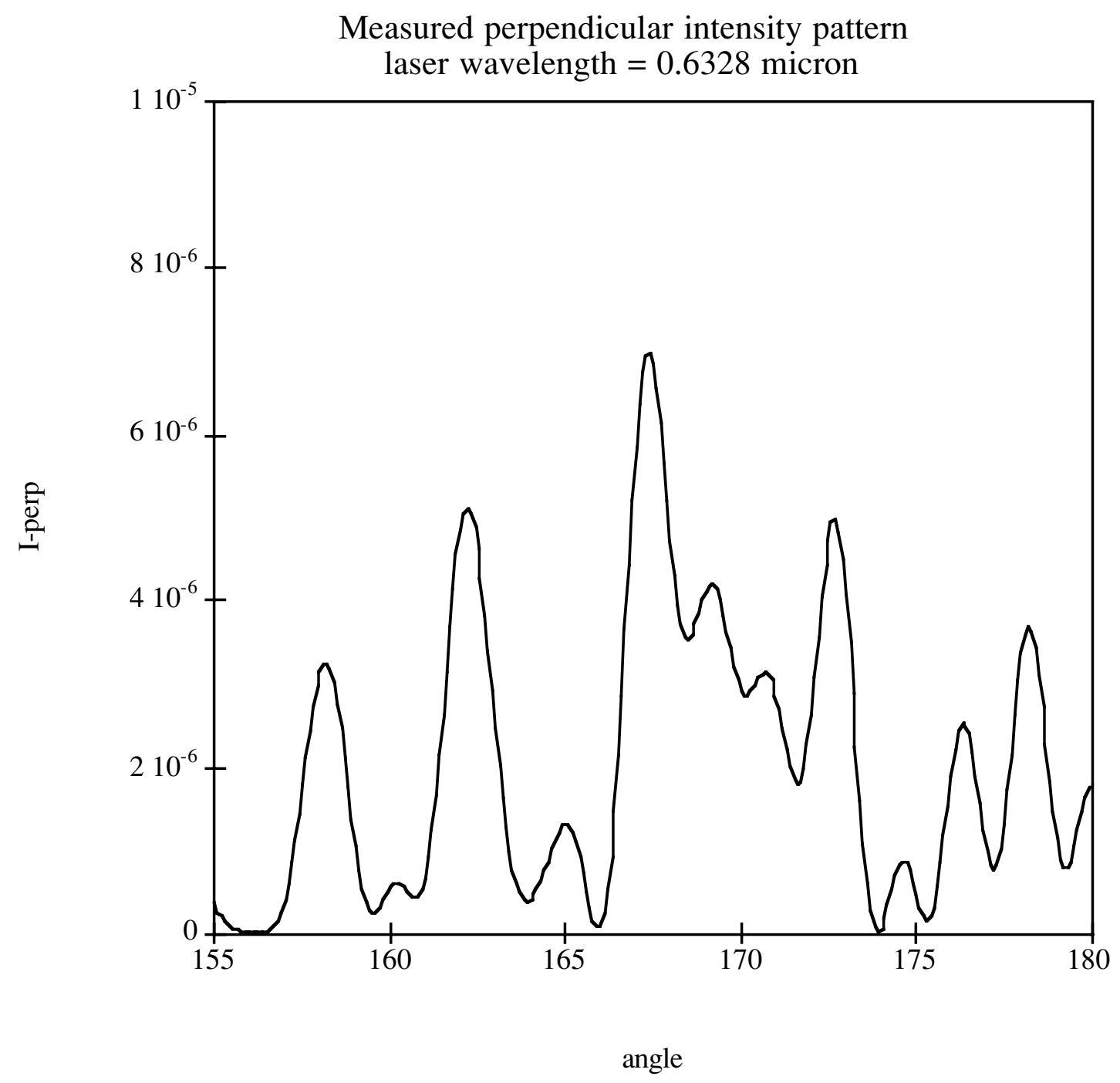


Fig. 6

Vertically elongated elliptic cross-section n-para (solid line) and n-perp (dotted line) $\mathrm{x} * * 2 / \mathrm{a} * * 2+\mathrm{y} * * 2 / \mathrm{b} * * 2=1$ $\mathrm{a}=19.5$ micron $\mathrm{b}=19.5-20.475$ micron

0
0
0
0
0
0
0
0
0
0
0
0

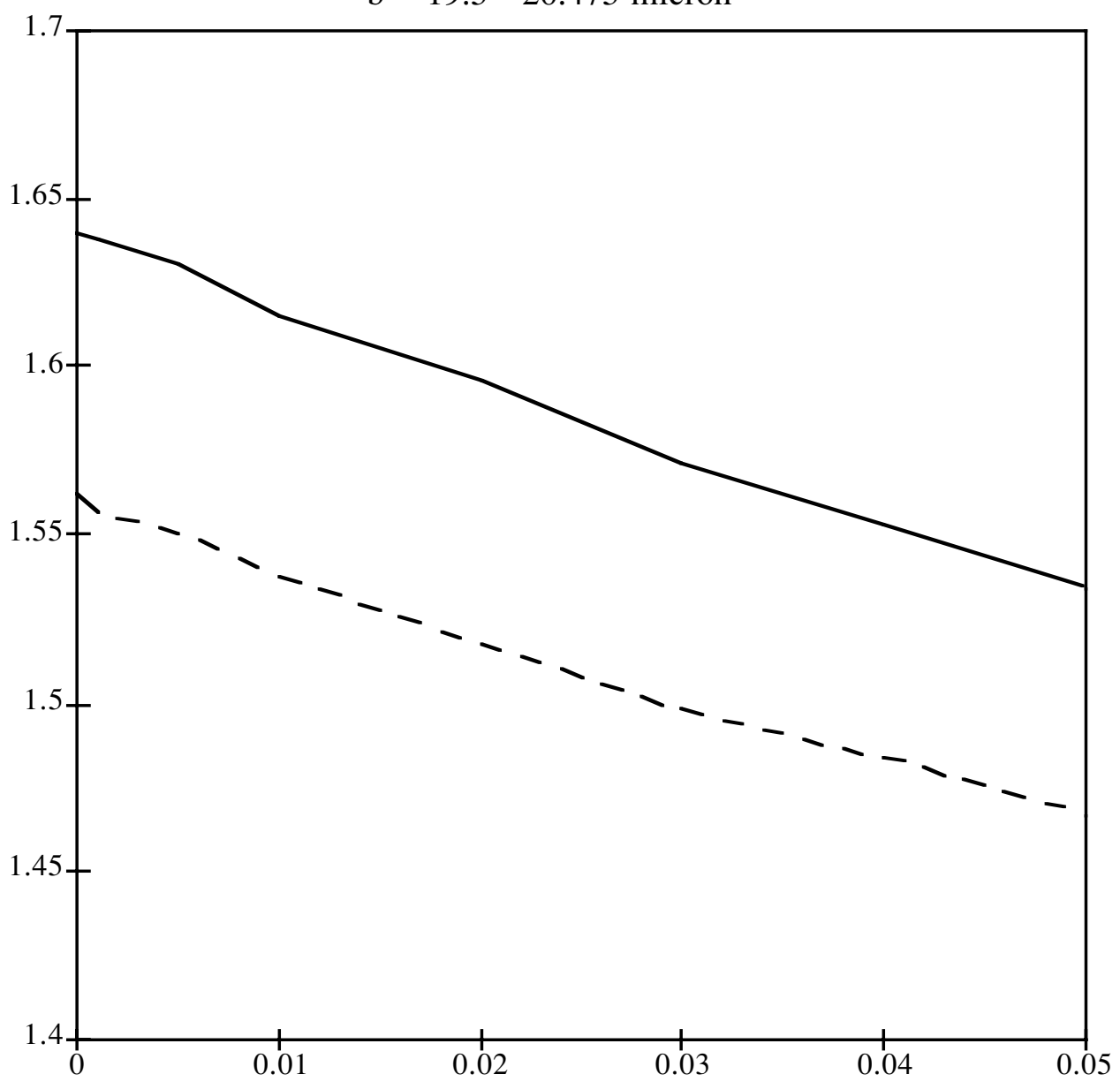

ellipticity 
Fig.7

Horizontally elongated elliptic cross-sections

n-para (solid line) and n-perp (dotted line)

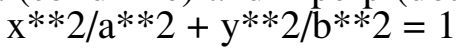

$\mathrm{a}=19.5-20.475$ micron

$\mathrm{b}=19.5$ micron

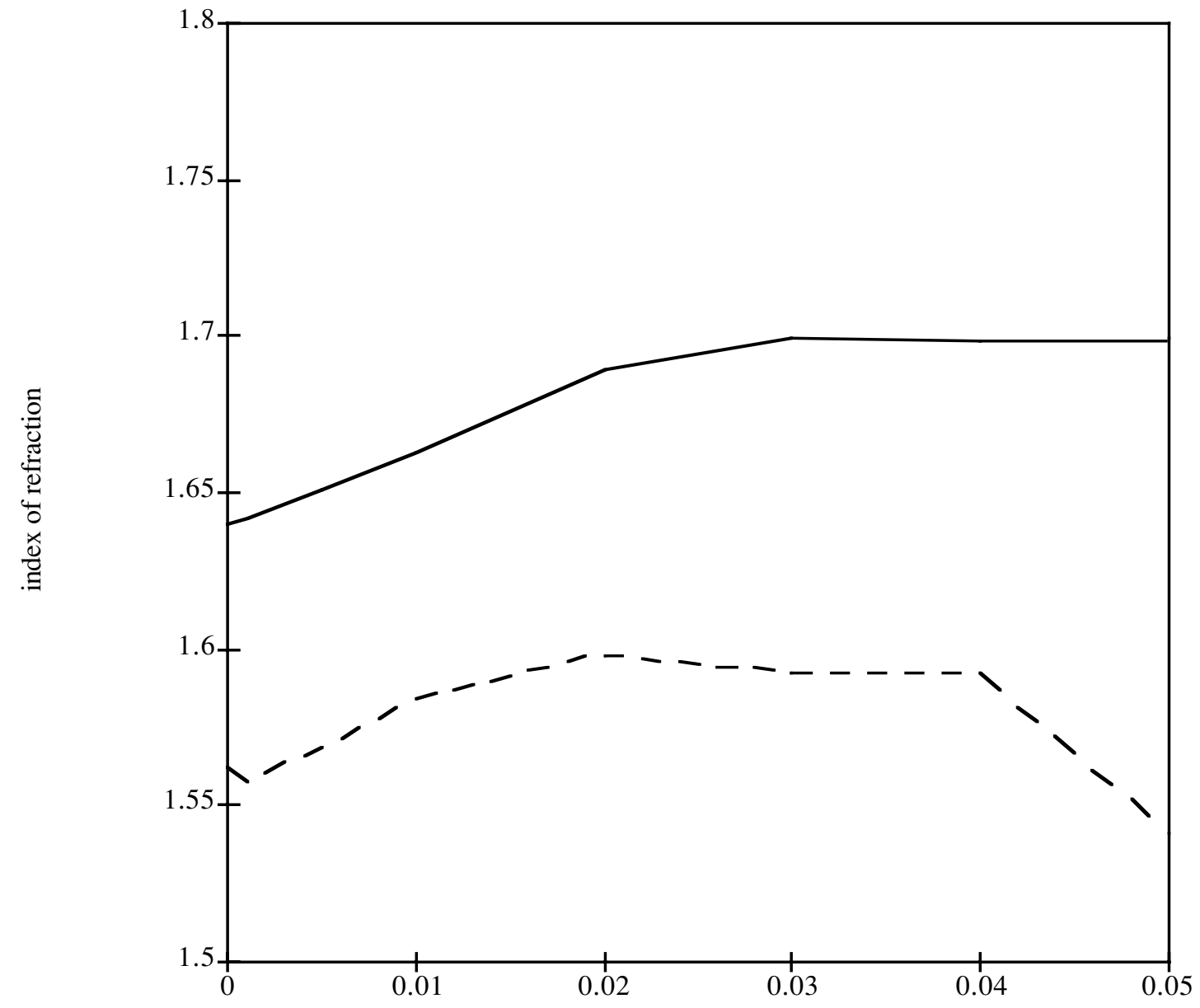

ellipticity 
Fig. 8

Elliptic cross-section fibers averaged over 8 orientations n-para (solid line) and n-perp (dotted line)

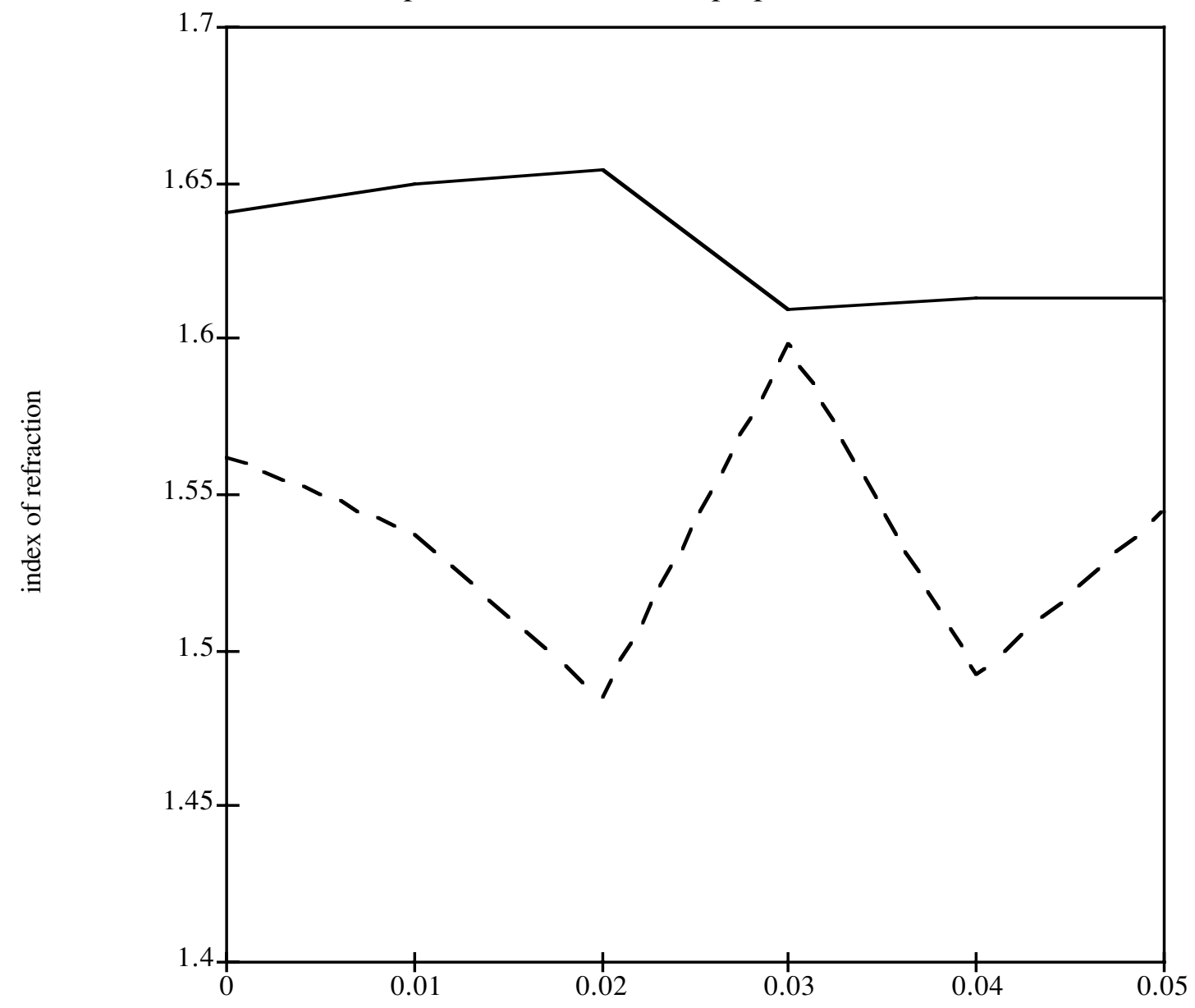

ellipticity 
Fig. 9

$$
\begin{gathered}
\mathrm{D}=19.5 \text { micron } \\
\mathrm{n} \text {-papa }=1.640
\end{gathered}
$$

The flat section is located at 3 o'clock position with the arc angle at 45 degrees

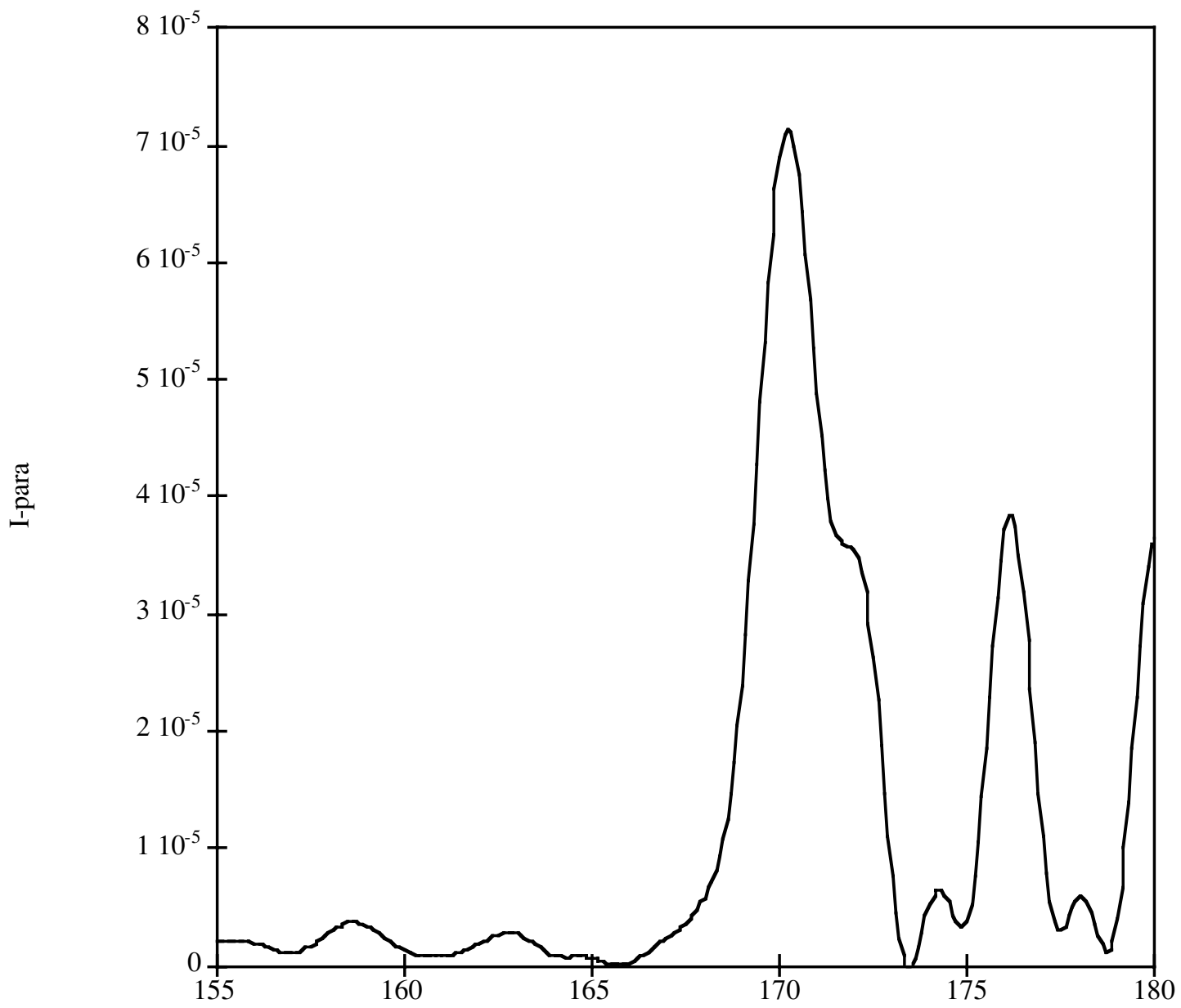

ANGLE(DEG) 
Fig. 10

$$
\begin{gathered}
\mathrm{D}=19.5 \text { micron } \\
\mathrm{n} \text {-perp }=1.562
\end{gathered}
$$

The flat section is located at 3 o'clock position with the arc angle at 45 degrees

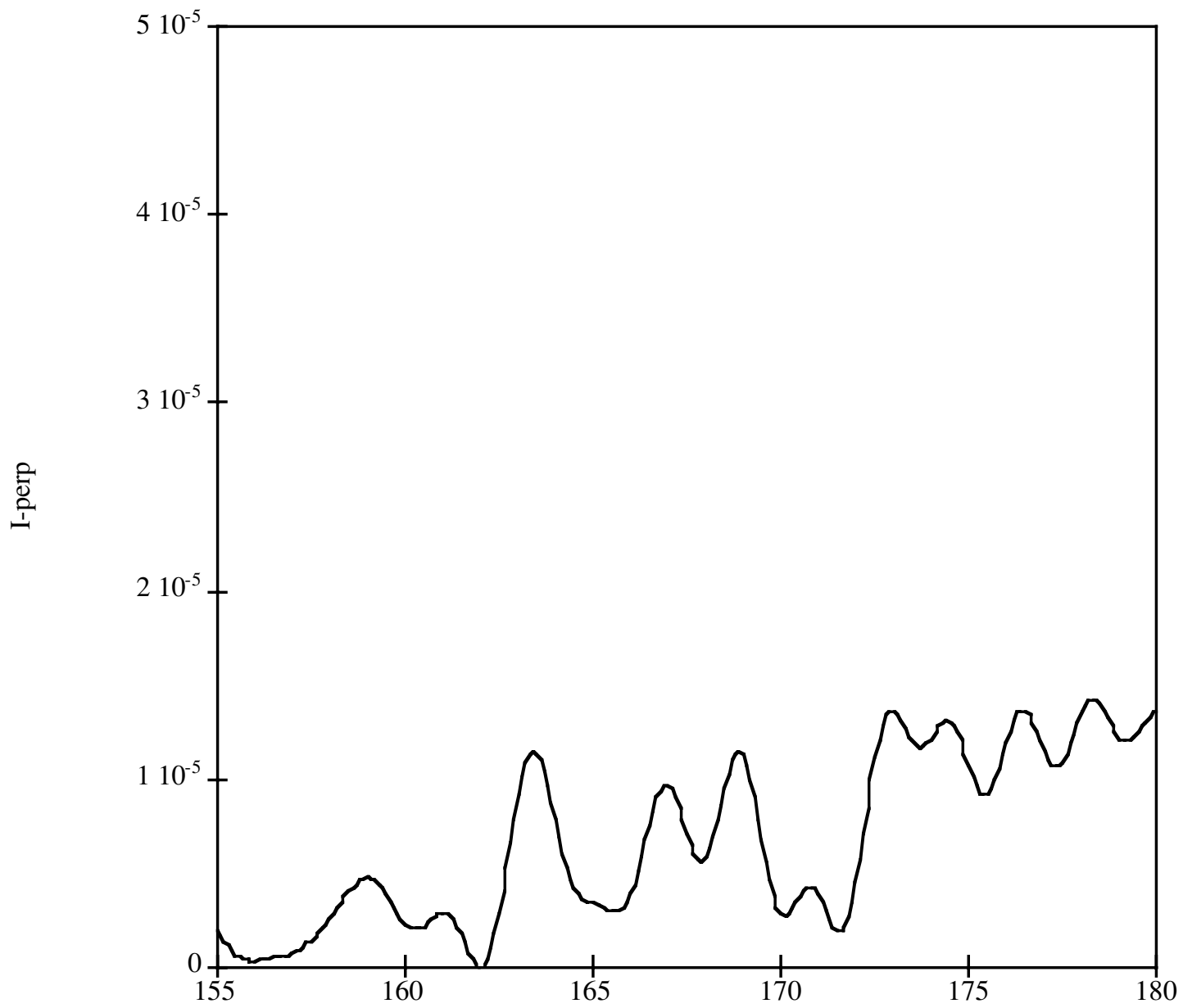

ANGLE(DEG) 
Fig. 11

semi-circle and flat cross-section fiber over 4 orientations

$$
\begin{gathered}
\mathrm{D}=19.5 \text { micron } \\
\mathrm{n} \text {-para }=1.640 \\
\mathrm{n} \text {-perp }=1.562
\end{gathered}
$$

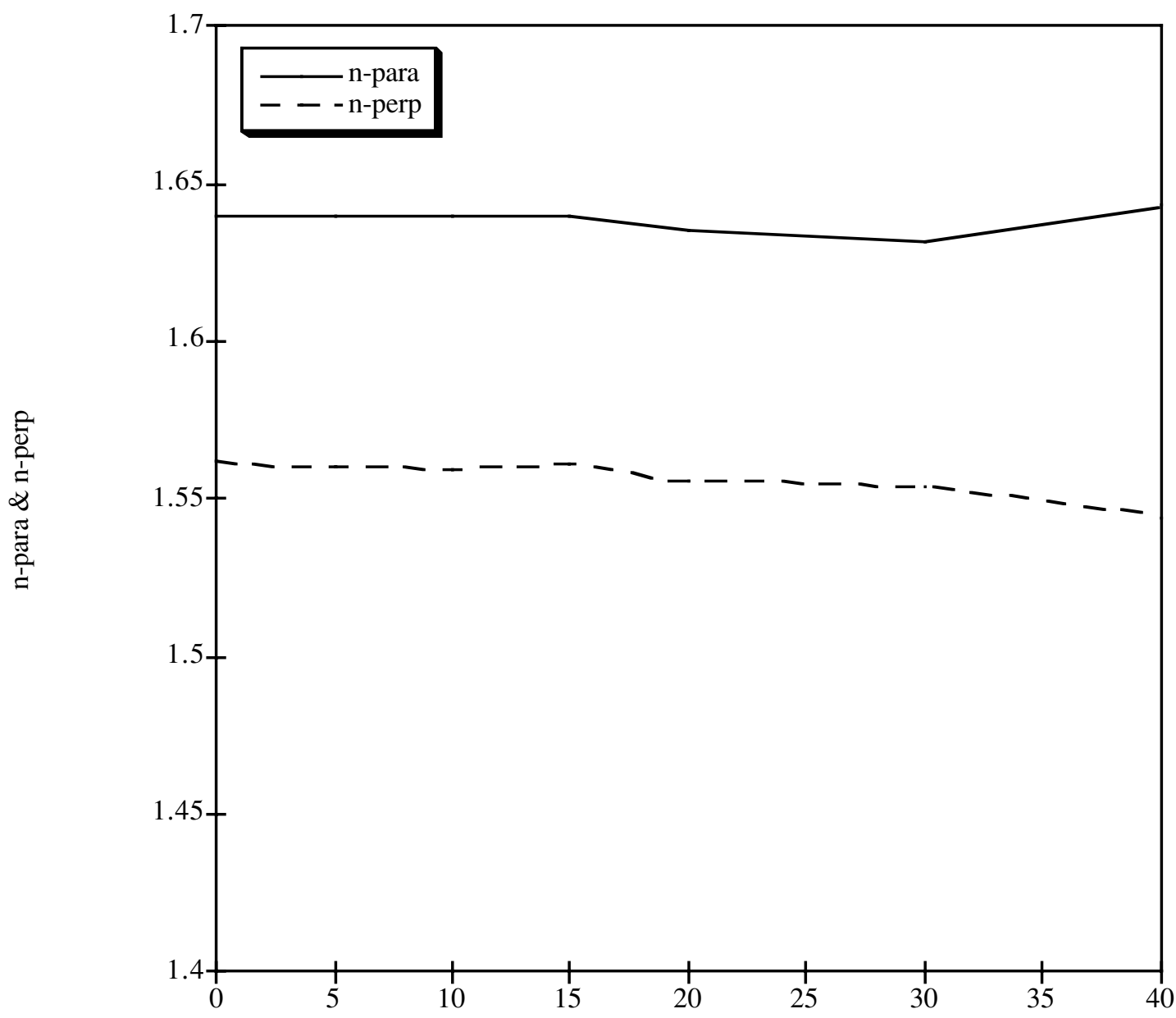

total flat section (deg) 
Fig. 12

The diameter of the inner layer is $10 \%$ of the outter layer. The inner density and the dielectric constant is increased by $50 \%$ relative to the outer density.

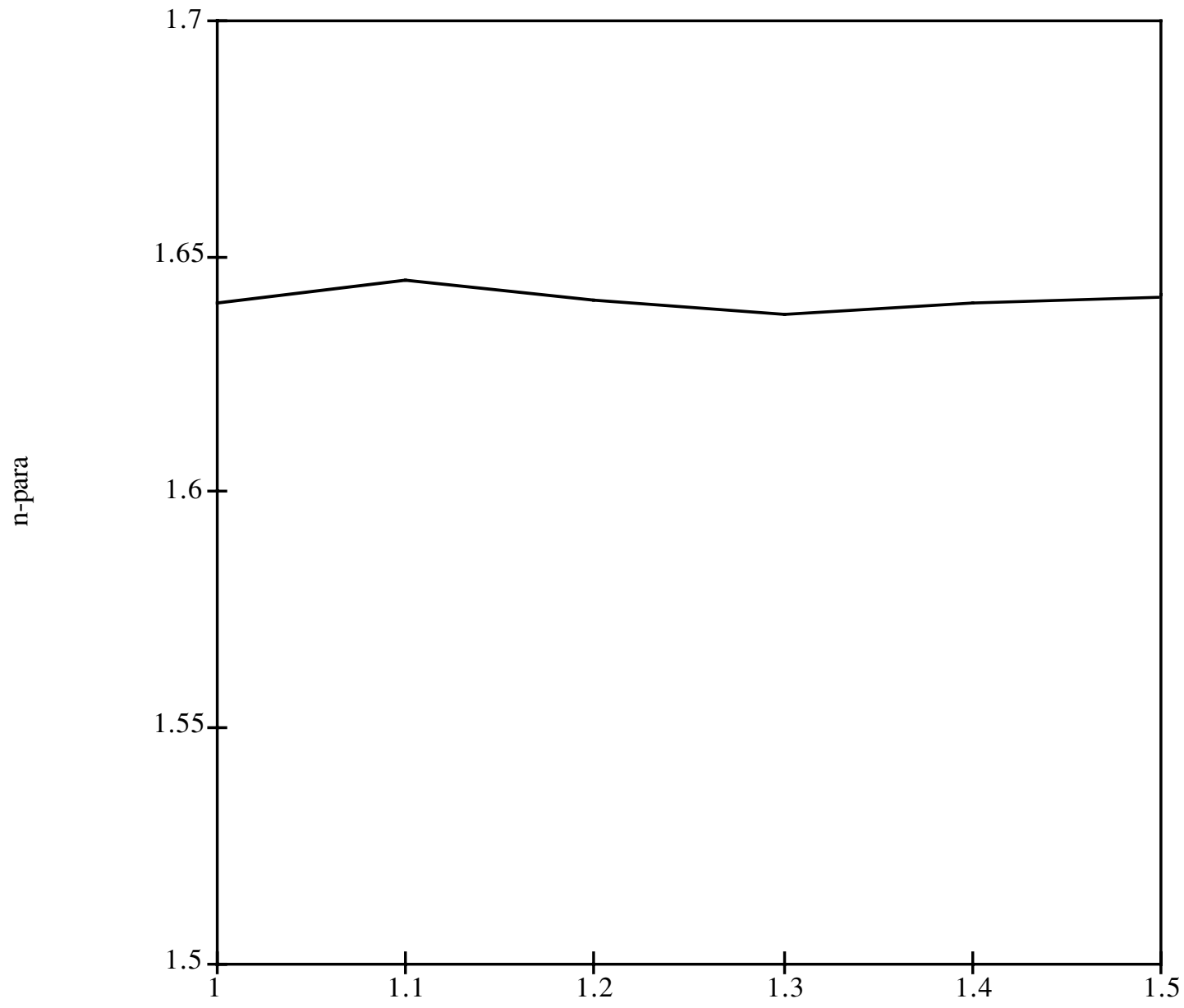

relative dielectric constant of the 2nd layer 
Fig. 13

The diameter of the inner layer is $10 \%$ of the outer layer. The inner density and the dielectric constant is increased by $50 \%$ relative to the outer density.

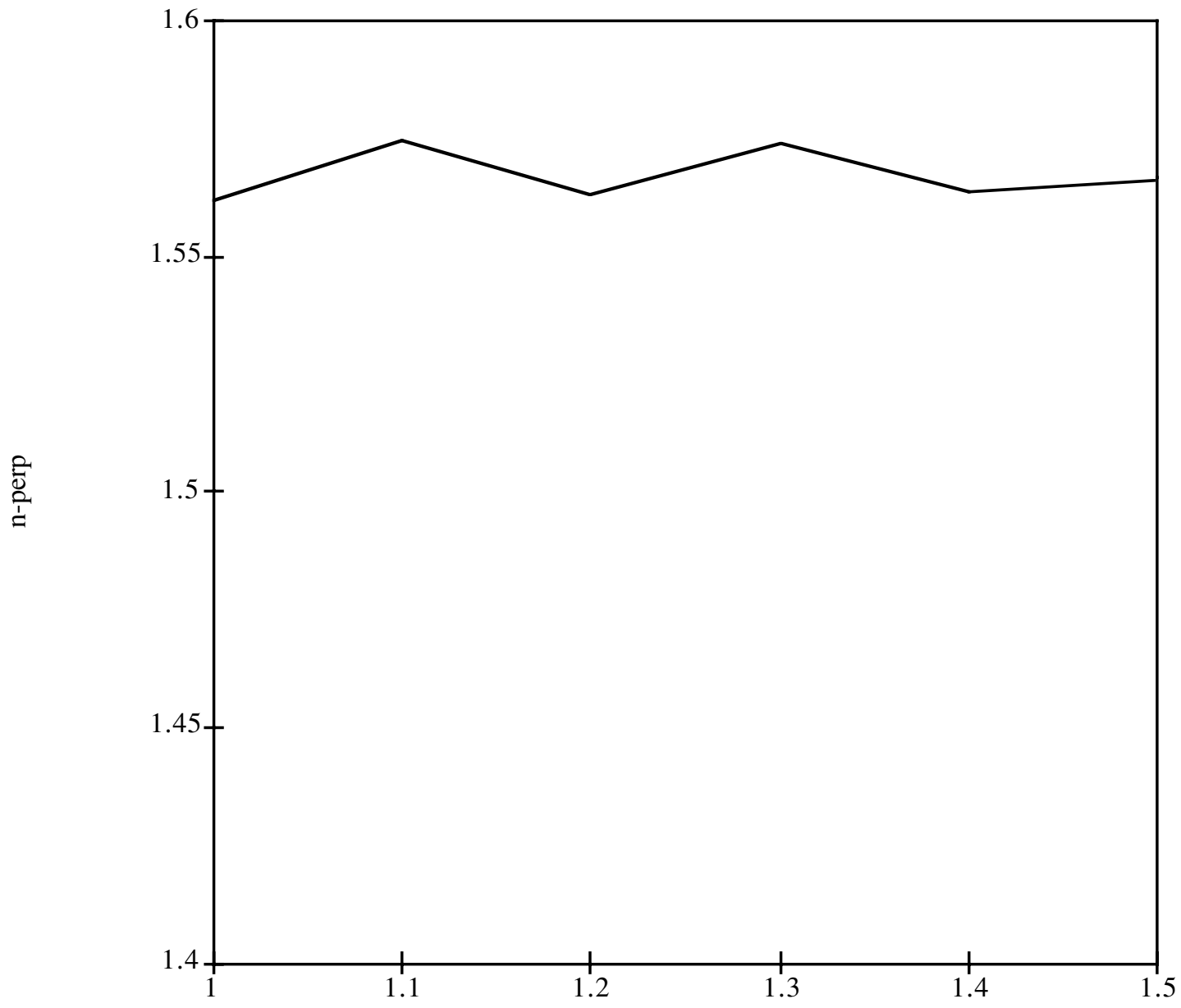

relative dielectric constant of the 2 nd layer 
Fig. 14

Parallel intensity pattern by a bundle consisting of four identical single fibers located at noon, 3 o'clock, 6 o'clock, and 9 o'clock positions. The distance between the two fibers on the same axis is 7.5 times the diameter

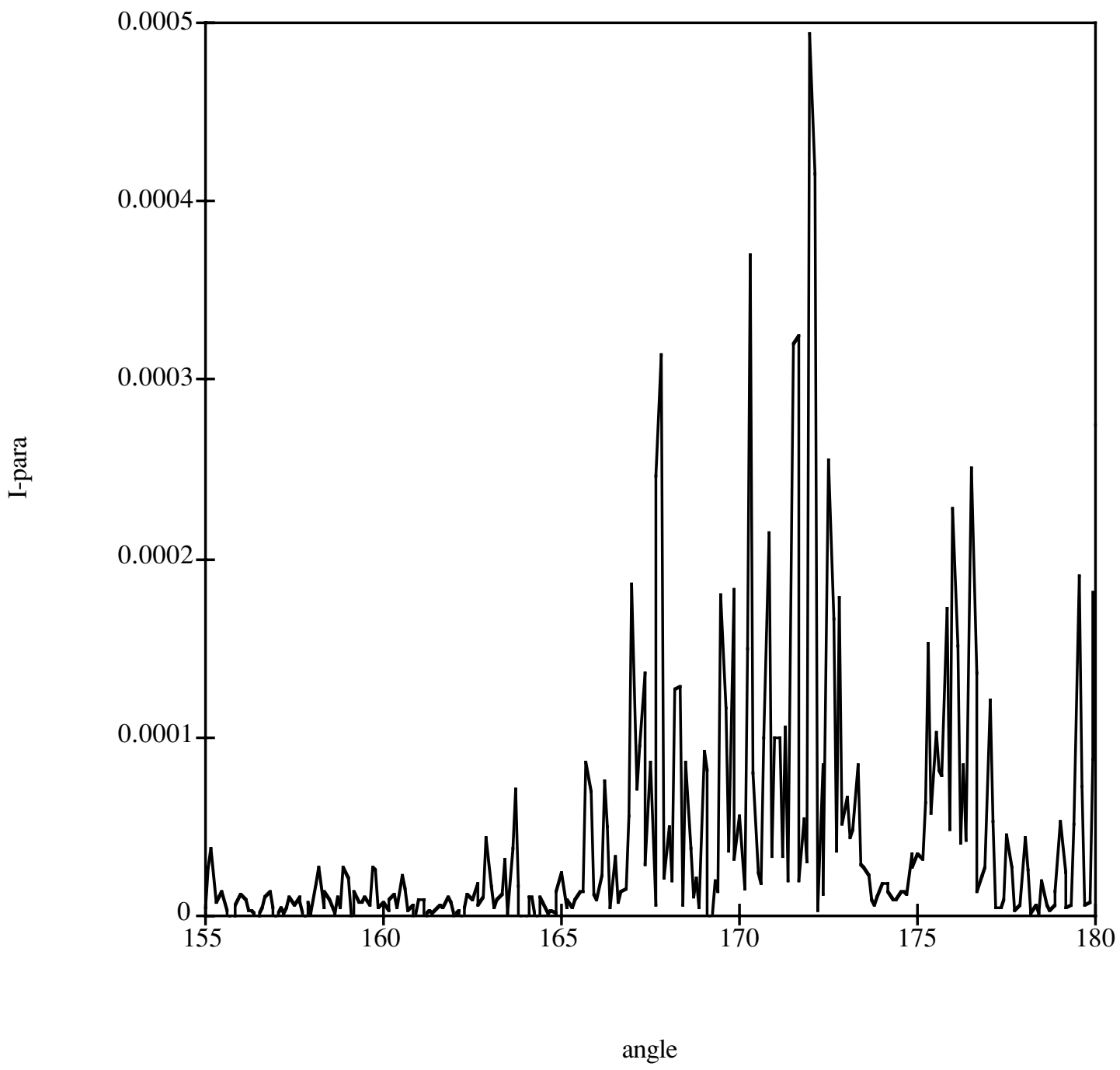


Fig. 15

A bundle with the same four single fibers as in Fig. 14. The distance between two fibers on the same axis is reduced to 1.5 times the diamater.

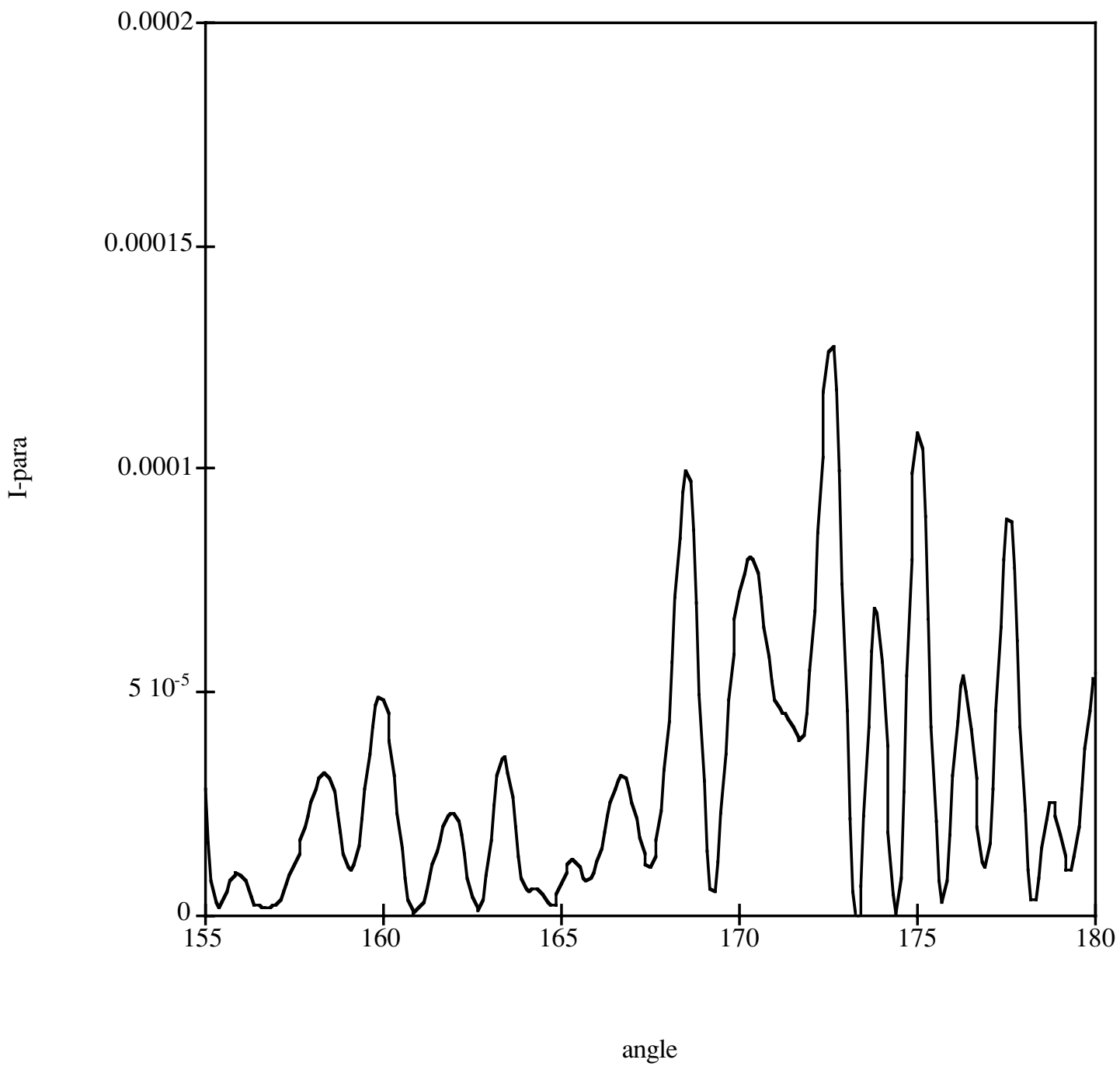


Fig. 16

Indices of refraction for the bundles consisting of four single fibers. The distance between two fibers is increased from 1.5 times to 7.5 times the diameter.

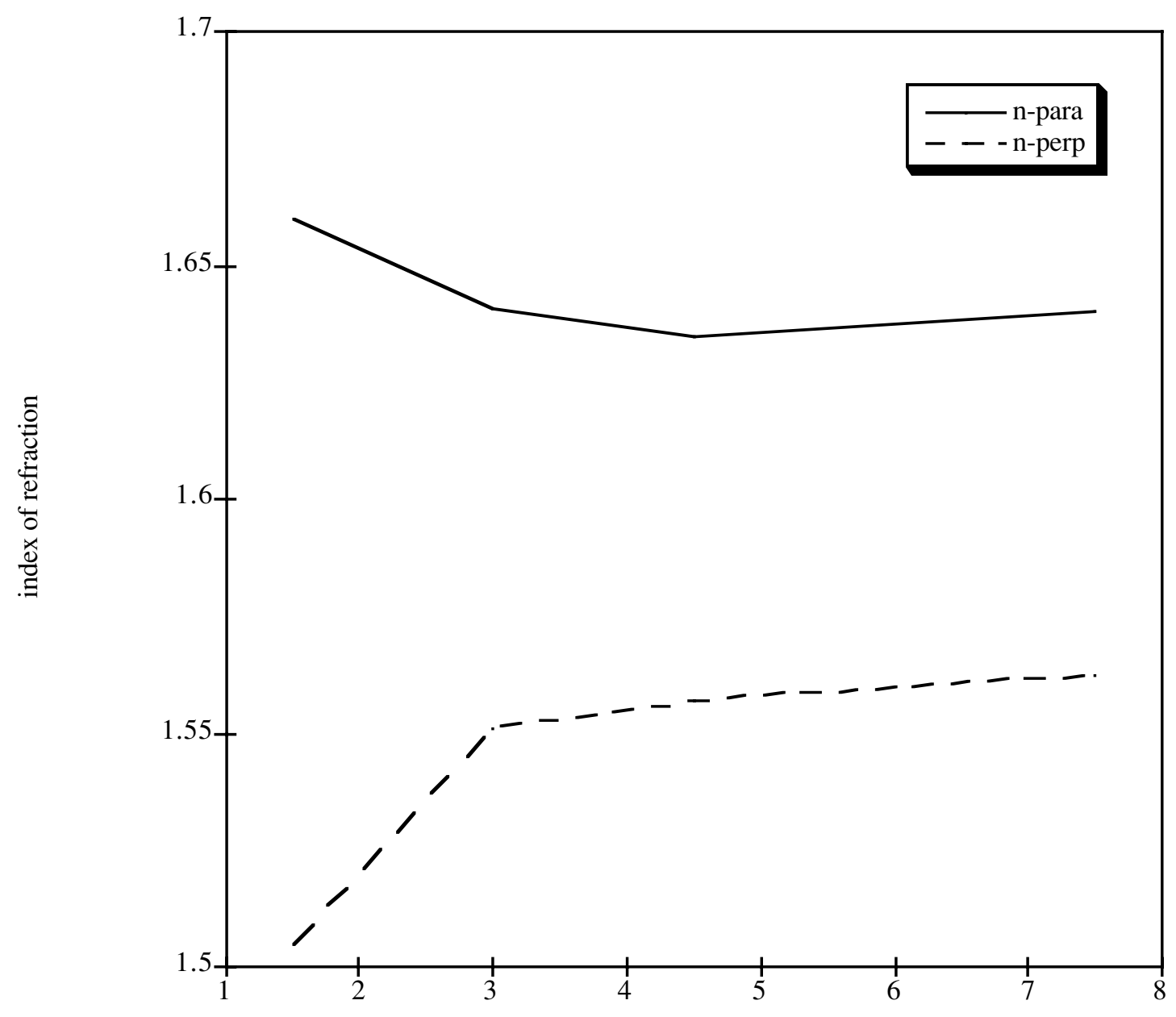

distance / diameter 
Fig. 17

Parallel intensity pattern for a bundle consisting of 19 identical fibers.

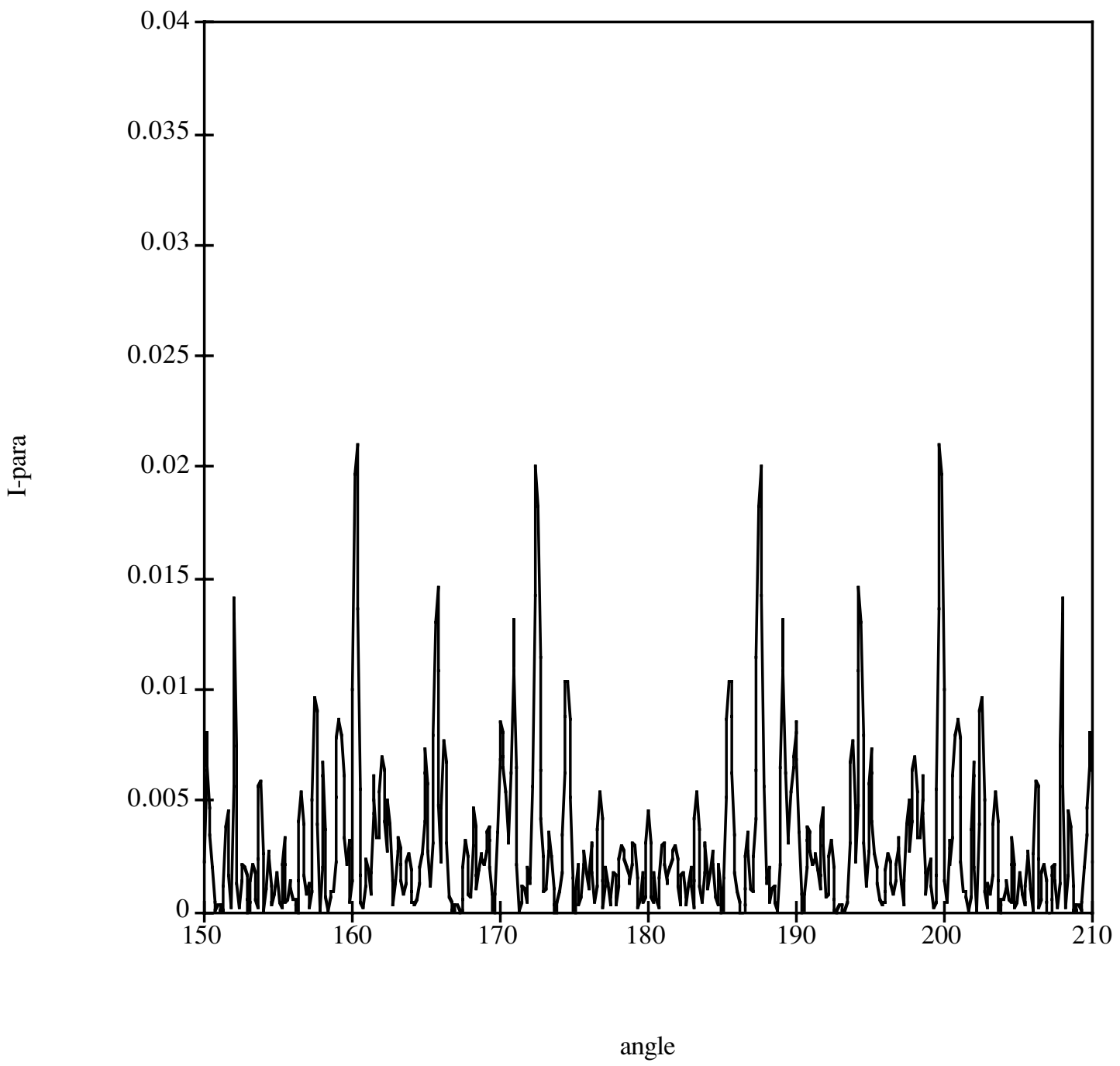


Fig. 18

Perpendicular intensity pattern for a bundle consisting of 19 fibers.

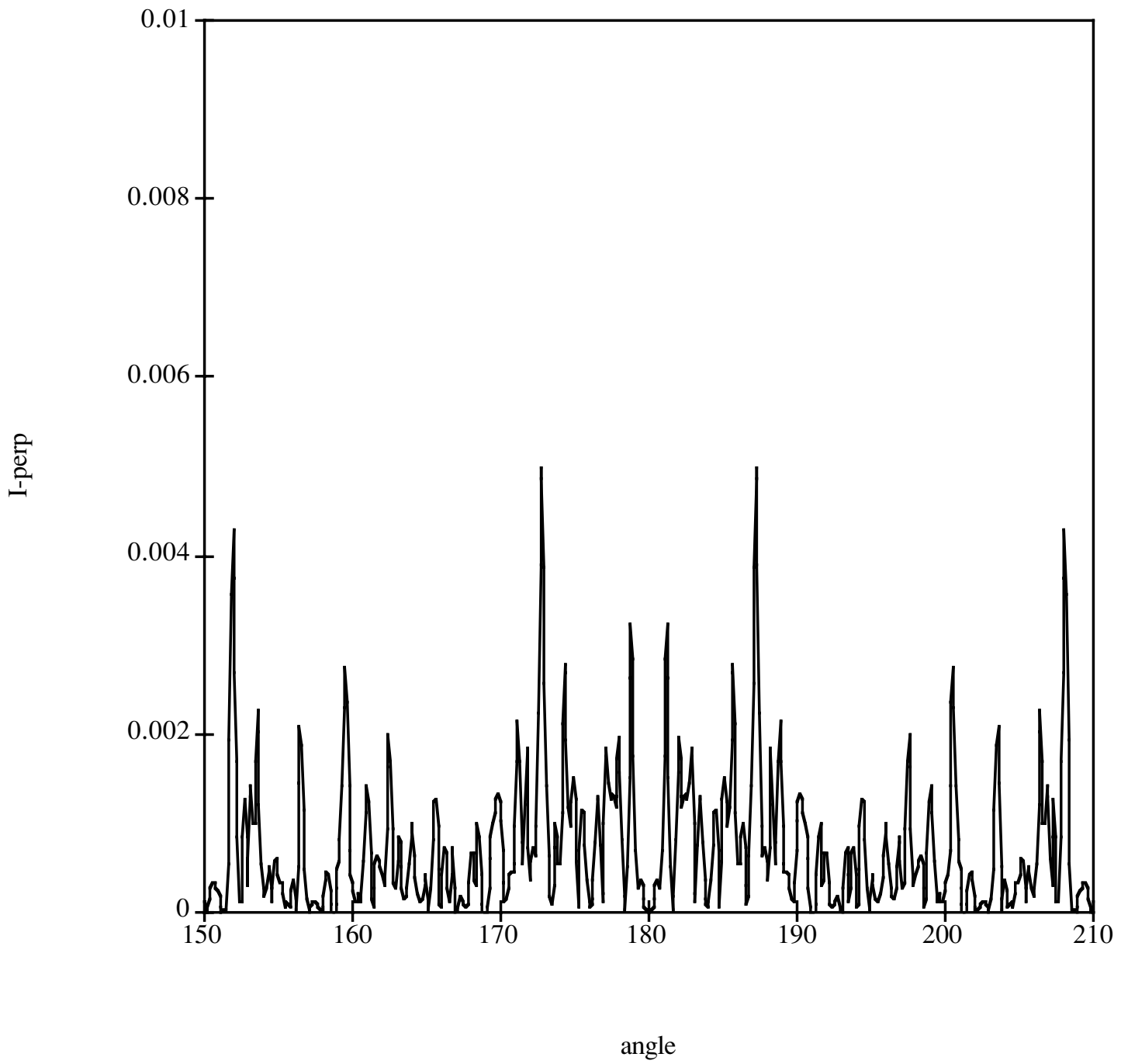


Fig. 19

Parallel intensity pattern with an absorption of $0.1 \%$

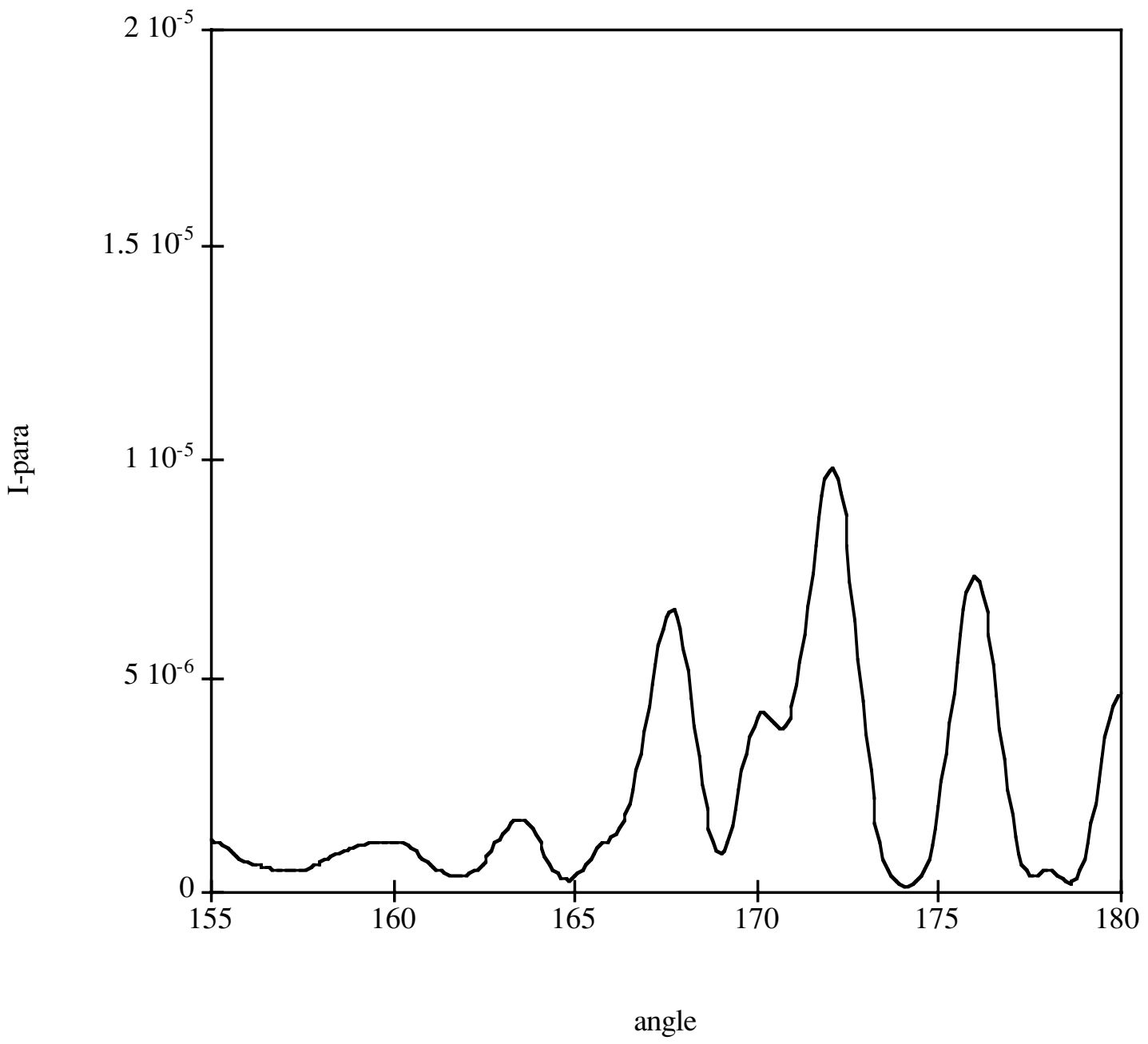


Fig. 20

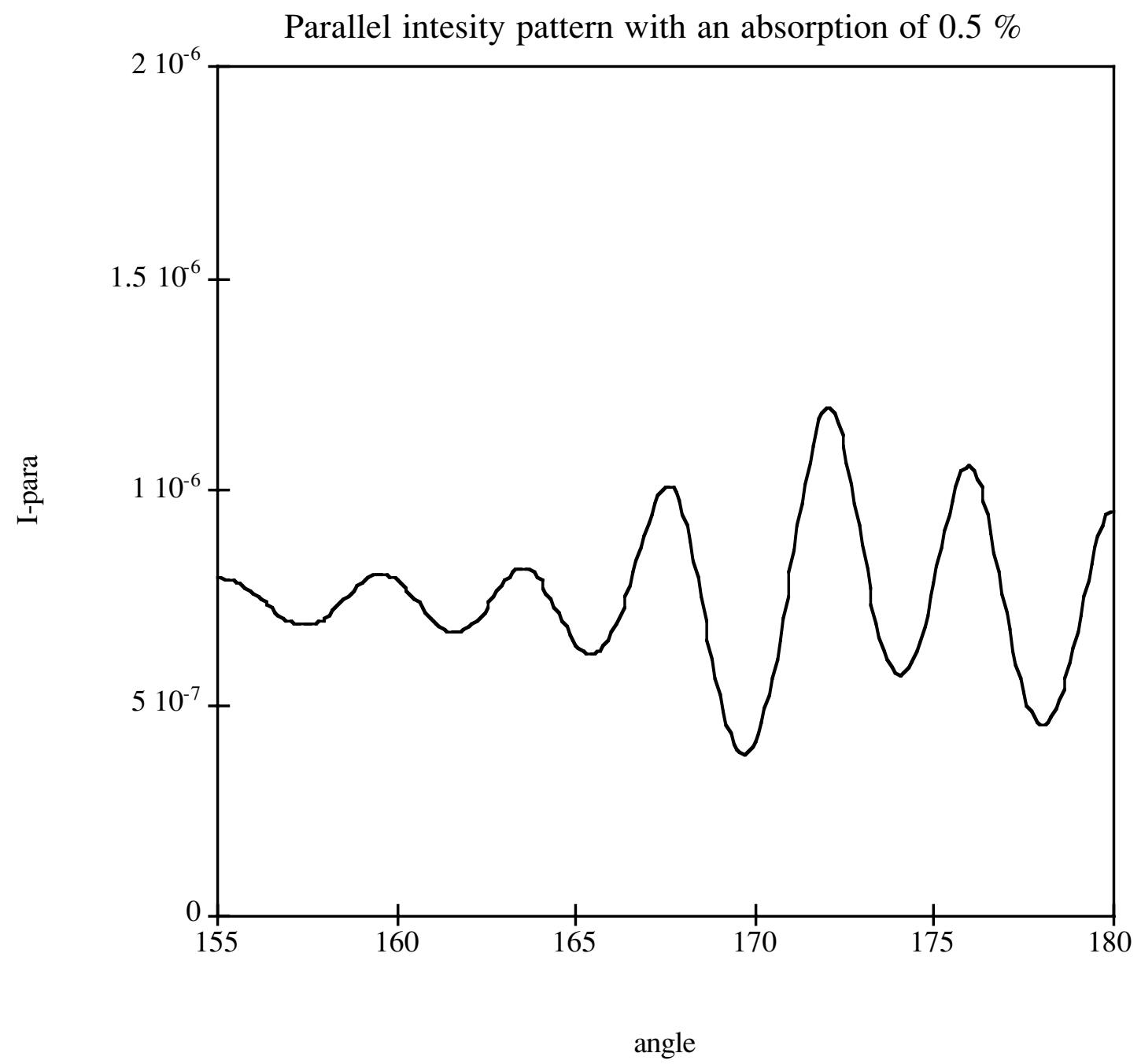




\section{DuPont_20B_C DATA ANALYSIS in REAL SPACE -}

Table 1

DuPont_20B_C_V_01:

$\begin{array}{lccll}\text { nr } & \text { npa } & \text { D } & \text { n-para } & \text { distance } \\ & & & & \\ 13 & 112 & 0.1924 \mathrm{E}-04 & 0.1611 \mathrm{E}+01 & 0.26178101 \mathrm{E}-01 \\ 14 & 110 & 0.1926 \mathrm{E}-04 & 0.1609 \mathrm{E}+01 & 0.26328753 \mathrm{E}-01 \\ 12 & 114 & 0.1922 \mathrm{E}-04 & 0.1613 \mathrm{E}+01 & 0.26344983 \mathrm{E}-01 \\ 4 & 112 & 0.1906 \mathrm{E}-04 & 0.1611 \mathrm{E}+01 & 0.26548759 \mathrm{E}-01 \\ 5 & 110 & 0.1908 \mathrm{E}-04 & 0.1609 \mathrm{E}+01 & 0.26641869 \mathrm{E}-01 \\ & & & & \\ \text { average } & & 0.1917 \mathrm{E}-04 & 0.1611 \mathrm{E}+01 & 0.26408493 \mathrm{E}-01\end{array}$

DuPont_20B_C_H_01:

$\mathrm{nr}$
27
27
74
26
73

average

DuPont_20B_C_V_02:

$\begin{array}{ll}\text { nr } & \text { npa } \\ 4 & 112 \\ 13 & 112 \\ 5 & 110 \\ 3 & 113 \\ 12 & 114\end{array}$

npa

$\mathrm{D}$

$0.1906 \mathrm{E}-04$ $0.1924 \mathrm{E}-04$ $0.1908 \mathrm{E}-04$ $0.1904 \mathrm{E}-04$ $0.1922 \mathrm{E}-04$

$0.1913 \mathrm{E}-04$

average

DuPont_20B_C_H_02:

$\begin{array}{ll}\text { nr } & \text { n } \\ 9 & 37 \\ 27 & 43 \\ 26 & 44 \\ 10 & 36 \\ 73 & 55\end{array}$

average

DuPont_20B_C_V_03:

$\begin{array}{ll}\text { nr } & \text { npa } \\ & \\ 13 & 112 \\ 14 & 110 \\ 12 & 114 \\ 15 & 108 \\ 4 & 111 \\ \text { average } & \end{array}$

D

$0.1924 \mathrm{E}-04$ $0.1926 \mathrm{E}-04$ $0.1922 \mathrm{E}-04$ $0.1928 \mathrm{E}-04$ $0.1906 \mathrm{E}-04$

0.1921E-04

$0.1916 \mathrm{E}-04$ $0.1952 \mathrm{E}-04$ $.1950 \mathrm{E}-04$ $0.1918 \mathrm{E}-04$

$0.1956 \mathrm{E}-04$

n-perp

$0.1442 \mathrm{E}+01$

$0.1443 \mathrm{E}+01$

$0.1453 \mathrm{E}+01$

$0.1444 \mathrm{E}+01$

$0.1454 \mathrm{E}+01$

$0.1447 \mathrm{E}+01$

n-para

$0.1611 \mathrm{E}+01$

$0.1611 \mathrm{E}+01$

$0.1609 \mathrm{E}+01$

$0.1612 \mathrm{E}+01$

$0.1613 \mathrm{E}+01$

$0.1611 \mathrm{E}+01$

n-perp

$0.1436 \mathrm{E}+01$

$0.1442 \mathrm{E}+01$

$0.1443 \mathrm{E}+01$

$0.1435 \mathrm{E}+01$

$0.1454 \mathrm{E}+01$

1442E+01

n-para

$0.1611 \mathrm{E}+01$

$0.1609 \mathrm{E}+01$

$0.1613 \mathrm{E}+01$

$0.1607 \mathrm{E}+01$

$0.1610 \mathrm{E}+01$

$0.1610 \mathrm{E}+01$

n-perp

$0.1442 \mathrm{E}+01$

$0.1436 \mathrm{E}+01$

$0.1443 \mathrm{E}+01$

$0.1454 \mathrm{E}+01$

$0.1444 \mathrm{E}+01$

$0.1444 \mathrm{E}+01$ distance

$0.22719331 \mathrm{E}-0$

$0.22866406 \mathrm{E}-01$

$0.22944942 \mathrm{E}-01$

$0.22957291 \mathrm{E}-01$

$0.22971480 \mathrm{E}-01$

0.22891890 E-01

distance

$0.24646761 \mathrm{E}-01$ $0.24746279 \mathrm{E}-01$ $0.24766097 \mathrm{E}-01$ $0.24809592 \mathrm{E}-01$ $0.24868902 \mathrm{E}-01$

$0.24767526 \mathrm{E}-01$

distance

$0.21321223 \mathrm{E}-01$ $0.21544587 \mathrm{E}-01$ $0.21798559 \mathrm{E}-0$ $0.21853502 \mathrm{E}-01$ $0.21888296 \mathrm{E}-01$

$0.21681233 \mathrm{E}-01$

distance

$0.24802605 \mathrm{E}-01$ $0.24819031 \mathrm{E}-0$ $0.25104647 \mathrm{E}-01$ $0.25203411 \mathrm{E}-01$ $0.25478638 \mathrm{E}-01$

$0.25081666 \mathrm{E}-01$

distance

$0.21505013 \mathrm{E}-01$ $0.21518789 \mathrm{E}-01$ $0.21536526 \mathrm{E}-01$ $0.21569732 \mathrm{E}-01$ $0.21957443 \mathrm{E}-01$

$0.21617501 \mathrm{E}-01$

DuPont_20B_C_V_04: 


$\begin{array}{ll}\text { nr } & \text { npa } \\ & \\ 13 & 112 \\ 14 & 110 \\ 12 & 114 \\ 3 & 113 \\ 4 & 111 \\ \text { average } & \end{array}$

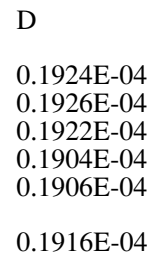

n-para

distance

DuPont_20B_C_H_04:

$\begin{array}{ll}\mathrm{nr} & \mathrm{np} \\ 26 & 45 \\ 8 & 39 \\ 9 & 38 \\ 15 & 115 \\ 9 & 37\end{array}$

D

$0.1950 \mathrm{E}-04$ $0.1914 \mathrm{E}-04$

$0.1916 \mathrm{E}-04$ $0.1928 \mathrm{E}-04$ $0.1916 \mathrm{E}-04$

$0.1611 \mathrm{E}+01$

$0.24595145 \mathrm{E}-01$

$0.1609 \mathrm{E}+0$ $0.24727671 \mathrm{E}-0$

$0.1613 \mathrm{E}+0$

$0.24771873 \mathrm{E}-01$

$0.1612 \mathrm{E}+01$

$0.25037442 \mathrm{E}-01$

$0.1610 \mathrm{E}+01$

$0.25119550 \mathrm{E}-01$

$0.1611 \mathrm{E}+01$

$0.24850336 \mathrm{E}-01$

DuPont_20B_C_V_05:

\begin{tabular}{ll} 
nr & npa \\
13 & 112 \\
12 & 114 \\
4 & 112 \\
3 & 113 \\
3 & 114 \\
\multicolumn{2}{l}{ average } \\
\end{tabular}

$0.1925 \mathrm{E}-04$

$\begin{array}{lc}\text { n-perp } & \text { distance } \\ 0.1444 \mathrm{E}+01 & 0.21810671 \mathrm{E}-01 \\ 0.1438 \mathrm{E}+01 & 0.21831900 \mathrm{E}-01 \\ 0.1437 \mathrm{E}+01 & 0.21927243 \mathrm{E}-01 \\ 0.1514 \mathrm{E}+01 & 0.22040425 \mathrm{E}-01 \\ 0.1436 \mathrm{E}+01 & 0.22073055 \mathrm{E}-01 \\ 0.1454 \mathrm{E}+01 & 0.21936659 \mathrm{E}-01\end{array}$

n-para

distance

$0.1611 \mathrm{E}+01$

$0.1613 \mathrm{E}+01$

$0.1611 \mathrm{E}+01$

$0.1612 \mathrm{E}+01$

$0.1613 \mathrm{E}+01$

$0.1906 \mathrm{E}-04$

$0.1904 \mathrm{E}-04$

0.1904E-04

$0.1612 \mathrm{E}+01$

0.24094107E-01

$0.24104987 \mathrm{E}-01$

$0.24179653 \mathrm{E}-01$

$0.24227193 \mathrm{E}-01$

$0.24294433 \mathrm{E}-01$

$0.1912 \mathrm{E}-04$

$0.24180075 \mathrm{E}-01$

DuPont_20B_C_H_05:

$\begin{array}{lc}\text { nr } & \text { np } \\ & \\ 26 & 44 \\ 27 & 43 \\ 9 & 37 \\ 73 & 55 \\ 26 & 45 \\ & \end{array}$

D

n-perp

distance

$0.1443 \mathrm{E}+01$

$0.1442 \mathrm{E}+0$

$0.1436 \mathrm{E}+0$

$0.1454 \mathrm{E}+01$

$0.1444 \mathrm{E}+01$

$0.22066533 \mathrm{E}-01$

$0.22191597 \mathrm{E}-01$

$0.22325594 \mathrm{E}-01$

$0.22347860 \mathrm{E}-01$

$0.22482005 \mathrm{E}-01$

$0.1950 \mathrm{E}-04$

$0.1444 \mathrm{E}+01$

$0.22282718 \mathrm{E}-01$

DuPont_20B_C_V_AVG:

$\begin{array}{ll}\mathrm{nr} & \mathrm{np} \\ 13 & 112 \\ 14 & 110 \\ 12 & 114 \\ 4 & 112 \\ 3 & 113\end{array}$

$$
\begin{aligned}
& \text { D } \\
& 0.1924 \mathrm{E}-04 \\
& 0.1926 \mathrm{E}-04 \\
& 0.1922 \mathrm{E}-04 \\
& 0.1906 \mathrm{E}-04 \\
& 0.1904 \mathrm{E}-04 \\
& 0.1916 \mathrm{E}-04
\end{aligned}
$$

n-para

$0.1611 \mathrm{E}+01$ $0.1609 \mathrm{E}+01$

$0.1613 \mathrm{E}+01$

$0.1611 \mathrm{E}+01$

$0.1612 \mathrm{E}+01$

$0.1611 \mathrm{E}+01$

n-perp

$0.1442 \mathrm{E}+01$

$0.1436 \mathrm{E}+01$

$0.1443 \mathrm{E}+01$

$0.1454 \mathrm{E}+01$

$0.1444 \mathrm{E}+01$

$0.1444 \mathrm{E}+01$ distance

$0.24787917 \mathrm{E}-01$ $0.24941581 \mathrm{E}-01$ $0.24949121 \mathrm{E}-01$

$0.25153979 \mathrm{E}-01$

$0.25173292 \mathrm{E}-01$

$0.25001178 \mathrm{E}-01$

distance

$0.21622581 \mathrm{E}-01$

$0.21666141 \mathrm{E}-01$

$0.21814882 \mathrm{E}-01$

$0.21829574 \mathrm{E}-0$

$0.21856813 \mathrm{E}-01$

0.21757998E-01

\begin{tabular}{lcllll}
\hline position & D-para & n-para & D-perp & n-perp & biref \\
1 & $0.1917 \mathrm{E}-04$ & $0.1611 \mathrm{E}+01$ & $0.1989 \mathrm{E}-04$ & $0.1447 \mathrm{E}+01$ & 0.164 \\
2 & $0.1913 \mathrm{E}-04$ & $0.1611 \mathrm{E}+01$ & $0.1956 \mathrm{E}-04$ & $0.1442 \mathrm{E}+01$ & 0.169 \\
3 & $0.1921 \mathrm{E}-04$ & $0.1610 \mathrm{E}+01$ & $0.1962 \mathrm{E}-04$ & $0.1444 \mathrm{E}+01$ & 0.166 \\
4 & $0.1916 \mathrm{E}-04$ & $0.1611 \mathrm{E}+01$ & $0.1925 \mathrm{E}-04$ & $0.1454 \mathrm{E}+01$ & 0.157 \\
5 & $0.1912 \mathrm{E}-04$ & $0.1612 \mathrm{E}+01$ & $0.1962 \mathrm{E}-04$ & $0.1444 \mathrm{E}+01$ & 0.168 \\
AVG & $0.1916 \mathrm{E}-04$ & $0.1611 \mathrm{E}+01$ & $0.1962 \mathrm{E}-04$ & $0.1444 \mathrm{E}+01$ & 0.167
\end{tabular}


$1-5$

$0.1916 \mathrm{E}-04$

$0.1611 \mathrm{E}+01$

0.1959E-04

$0.1446 \mathrm{E}+01$

$0.4214 \mathrm{E}-02$

0.2041E-06
$0.6325 \mathrm{E}-03$

sq(s.d.) $\quad 0.3188 \mathrm{E}-07$
(1)
0.165

0.00426 
Table 2

Many Point Measurement

\begin{tabular}{lccc}
\multicolumn{1}{c}{ Fiber } & $\begin{array}{c}\text { Overall } \\
\text { average }\end{array}$ & $\begin{array}{c}\text { Outliers } \\
\text { removed }\end{array}$ & $\begin{array}{c}\text { Number of } \\
\text { outliers }\end{array}$ \\
$\begin{array}{l}\text { DuPont 24-A4 } \\
\text { (30 Points) }\end{array}$ & $0.039(0.0169)$ & $0.042(0.010)$ & 4 \\
DuPont 6-20 & 0.097 & 0.114 & 8 \\
(30 Points) & $(0.040)$ & $(0.011)$ & 7 \\
DuPont 6-22 & 0.147 & & \\
(30 Points) & $(0.034)$ & 0.138 & \\
Wellman 4 & 0.052 & $(0.014)$ & 6 \\
(22 Points) & $(0.035)$ & 0.067 & \\
\end{tabular}

Note: standard deviation in ( ). 


\section{External Distribution}

Plasma Research Laboratory, Australian National University, Australia

Professor I.R. Jones, Flinders University, Australia

Professor João Canalle, Instituto de Fisica DEQ/IF - UERJ, Brazil

Mr. Gerson O. Ludwig, Instituto Nacional de Pesquisas, Brazil

Dr. P.H. Sakanaka, Instituto Fisica, Brazil

The Librarian, Culham Laboratory, England

Mrs. S.A. Hutchinson, JET Library, England

Professor M.N. Bussac, Ecole Polytechnique, France

Librarian, Max-Planck-Institut für Plasmaphysik, Germany

Jolan Moldvai, Reports Library, Hungarian Academy of Sciences, Central Research Institute for Physics, Hungary

Dr. P. Kaw, Institute for Plasma Research, India

Ms. P.J. Pathak, Librarian, Institute for Plasma Research, India

Ms. Clelia De Palo, Associazione EURATOM-ENEA, Italy

Dr. G. Grosso, Instituto di Fisica del Plasma, Italy

Librarian, Naka Fusion Research Establishment, JAERI, Japan

Library, Laboratory for Complex Energy Processes, Institute for Advanced Study, Kyoto University, Japan

Research Information Center, National Institute for Fusion Science, Japan

Dr. O. Mitarai, Kyushu Tokai University, Japan

Dr. Jiangang Li, Institute of Plasma Physics, Chinese Academy of Sciences, People's Republic of China

Professor Yuping Huo, School of Physical Science and Technology, People's Republic of China

Library, Academia Sinica, Institute of Plasma Physics, People's Republic of China

Librarian, Institute of Physics, Chinese Academy of Sciences, People's Republic of China

Dr. S. Mirnov, TRINITI, Troitsk, Russian Federation, Russia

Dr. V.S. Strelkov, Kurchatov Institute, Russian Federation, Russia

Professor Peter Lukac, Katedra Fyziky Plazmy MFF UK, Mlynska dolina F-2, Komenskeho Univerzita, SK-842 15 Bratislava, Slovakia

Dr. G.S. Lee, Korea Basic Science Institute, South Korea

Institute for Plasma Research, University of Maryland, USA

Librarian, Fusion Energy Division, Oak Ridge National Laboratory, USA

Librarian, Institute of Fusion Studies, University of Texas, USA

Librarian, Magnetic Fusion Program, Lawrence Livermore National Laboratory, USA

Library, General Atomics, USA

Plasma Physics Group, Fusion Energy Research Program, University of California at San Diego, USA

Plasma Physics Library, Columbia University, USA

Alkesh Punjabi, Center for Fusion Research and Training, Hampton University, USA

Dr. W.M. Stacey, Fusion Research Center, Georgia Institute of Technology, USA

Dr. John Willis, U.S. Department of Energy, Office of Fusion Energy Sciences, USA

Mr. Paul H. Wright, Indianapolis, Indiana, USA 
The Princeton Plasma Physics Laboratory is operated by Princeton University under contract with the U.S. Department of Energy.

\author{
Information Services \\ Princeton Plasma Physics Laboratory \\ P.O. Box 451 \\ Princeton, NJ 08543
}

Phone: 609-243-2750

Fax: 609-243-2751

e-mail: pppl_info@pppl.gov

Internet Address: http://www.pppl.gov 